\title{
Alúmina anódica porosa (AAP): arreglo de nanocrisoles de $\alpha$-alúmina de tamaño modulable ${ }^{\diamond}$
}

\section{Porous anodic alumina (PAA): modulation size $\alpha$-alumina nanocrucible array}

\author{
Ricardo González Campuzano,,, María Esther Mata Zamora**
}

\begin{abstract}
Due to the increasing interest in the synthesis of different structures at nanometric scale, porous anodic aluminas are an emerging alternative to the sophisticated and expensive methods used currently. In this work, we present a brief review on some recent experimental results to synthesize porous anodic aluminas with extra-large pore diameters (>200 nm), using mixtures of acids as electrolytes and high anodizing voltages. Additionally, we present studies related to thermal stability of porous anodic aluminas; these anodic aluminas are formed under standard conditions, using the most common electrolytes (sulfuric, oxalic and phosphoric acids). These studies have shown that anodic aluminas, initially amorphous, must transition through an elimination process of anions prior to the transformation to polycrystalline phases until them, finally achieve the most stable phase, $\alpha$-alumina. Finally, we mention some of the mostprominent applications these porous-anodic-alumina-nanostructures, obtained by non-conventional and heat treatment methods, might have.
\end{abstract}

KEYWORDS: porous anodic alumina (PAA), $\alpha$-alumina membranes, thermotreatment PAA.

RESUMEN: Debido al creciente interés en la síntesis de diferentes estructuras a escala nanométrica, las alúminas anódicas porosas son una alternativa emergente a los métodos más sofisticados y costosos que se utilizan actualmente. En este trabajo se presenta una breve revisión acerca de algunos resultados experimentales recientes para sintetizar alúminas anódicas porosas con diámetros de poro extra grandes (>200 nm), usando mezclas de ácidos como electrolitos y voltajes altos de anodizado. Adicionalmente, se presentan estudios relacionados con la estabilidad térmica de las alúminas anódicas porosas, formadas en condiciones estándar, usando los electrolitos más comunes (ácidos sulfúrico, oxálico y fosfórico). Dichos estudios han mostrado que la alúmina anódica, de inicio amorfa, debe transitar por un proceso de eliminación de aniones previo a la transformación de fases policristalinas hasta alcanzar la fase más estable, $\alpha$-alúmina. Finalmente, se mencionan algunas de las más destacadas aplicaciones que podrían tener las nanoestructuras obtenidas a partir de alúminas anódicas porosas obtenidas por métodos no convencionales y las tratadas térmicamente.

PALABRAS CLAVE: alúmina anódica porosa (AAP), membranas de $\alpha$-alúmina, termotratamiento de AAP.

Recibido: 26 de febrero, 2021. Aceptado: 8 de julio, 2021. Publicado: 17 de septiembre, 2021.

^Agradecemos a Omar Novelo y Josué E. Romero del Laboratorio Universitario de Microscopía Electrónica (LUME-IIM-UNAM) por las imágenes SEM.

* Universidad Nacional Autónoma de México, Instituto de Investigaciones en Materiales.

** Universidad Nacional Autónoma de México, Instituto de Ciencias Aplicadas y Tecnología.

- Autor de correspondencia: naedra@ciencias.unam.mx 


\section{Introducción}

El material de un crisol, además de soportar altas temperaturas y por ello ser estable térmicamente, también debe ser químicamente inerte. La alúmina en su fase cristalina alfa (o corindón) posee ambas propiedades y se le ha utilizado como material refractario en crisoles u hornos en los laboratorios de química, así como también en la industria cerámica (Gitzen, 1970). En general, el término alúmina se usa de manera indefinida en la literatura especializada para denotar los óxidos de aluminio hidratados (hidróxidos) u óxidos de aluminio parcialmente libres de agua (oxohidróxidos) o al corindón específicamente (Wefer y Misra, 1987). El significado más certero del término alúmina es en algunas ocasiones difícil de contextualizar; pero aquí el término es usado principalmente en el sentido de cualquier óxido de aluminio hidratado o anhidro tomado indistintamente, incluyendo cualquiera de las fases cristalinas y estado amorfo.

Ahora bien, si pensamos en otra de las aplicaciones del óxido de aluminio, es decir, como recubrimiento de superficies metálicas nos encontramos con dos aspectos muy interesantes. Uno, es la propiedad del aluminio por combinarse rápidamente con el oxígeno y formar una capa delgada de óxido superficial impenetrable y adherente que detiene el proceso de corrosión del aluminio metálico. La textura de esta película es muy regular, y bajo ciertas condiciones su espesor se puede controlar en el intervalo de los nanómetros a las decenas de micrómetro. El segundo aspecto es que las películas de óxido de aluminio que recubren la superficie del metal tienen la característica de formar una estructura de poros arreglados de forma más o menos regular en casos muy específicos conocida como alúmina anódica porosa (AAP). Esto último atrajo el interés de los investigadores en muchas delas actividades de desarrollo tecnológico y de investigación en el área de las nanociencias, debido al gran potencial de contar con un molde o plantilla para generar nanomateriales de diversa índole (Lee et al., 2014). El propósito de este trabajo es presentar un panorama general de temas de investigación relativamente recientes. Uno de ellos es el de poder modular las dimensiones del diámetro de poro mayor a los $200 \mathrm{~nm}$ obtenidos por métodos de anodizado electroquímico convencional. El otro tema involucra la modificación de la composición y estructura cristalina de la AAP para obtener un material cerámico nanoestructurado con las características deseables de estabilidad térmica y resistencia a medios corrosivos tanto ácidos como alcalinos.

Inicialmente, se realiza una breve descripción acerca de la composición y estructura de las AAP obtenida por métodos electroquímicos bajo condiciones estándar de corriente o potencial fijos. Posteriormente, se mencionan algunos estudios recientes relativos a la posibilidad de extender las dimensiones de los parámetros de las celdas de la AAP, como la distancia interporo y diámetro de poro para la generación de novedosos arreglos nanométricos, tales como nanoconcavidades formadas en la superficie del aluminio y nanodomos formados en el lado opuesto a la superficie porosa. Aunque, en la mayoría de las aplicaciones que se le han dado a las AAP, no se ha requerido el 
uso de tratamientos térmicos ni procesos de síntesis de nanoestructuras por arriba de la temperatura ambiente (Losic y Santos, 2015), resulta importante establecer que las AAP son susceptibles a cambios fisicoquímicos debido a su naturaleza amorfa y composición química. Es por ello que se hace una revisión de los estudios realizados en relación con la estabilidad térmica de las AAP y las propuestas para conseguir membranas de $\alpha$-alúmina porosa.

\section{Arreglo de celdas de óxido de aluminio anódico poroso (OAAP) o alúmina anódica porosa (AAP)}

En general, la AAP se describe como un arreglo vertical de celdas de óxido de aluminio dispuestas de forma normal a la superficie del aluminio (figura 1). El conjunto de celdas forma un arreglo de mínima energía conocida como empaquetamiento hexagonal compacto. Cada celda contiene un poro al centro que se encuentra sellado en la base por un óxido anódico tipo capa barrera de geometría semiesférica. El mecanismo de crecimiento y formación de las celdas lo han descrito detalladamente Abdel-Karim y El-Raghy (2016), Lee et al. (2014) y Runge (2018). La estructura generalmente se define por varios parámetros estructurales, tales como la distancia interporo $\left(D_{\text {int }}\right)$, diámetro de poro $\left(D_{p}\right)$, espesor de la capa barrera $\left(t_{b}\right)$, espesor de la pared de poro $\left(t_{w}\right)$, densidad de poro $\left(\delta_{p}\right)$ y la porosidad (P). Se sabe que estos parámetros, que constituyen las características más notables de las AAP, dependen de las condiciones del anodizado: tipo y concentración del electrolito, potencial de anodizado, densidad de corriente, temperatura, entre otros (Lee et al., 2014; Sulka, 2008). En la figura 1 se muestran imágenes, tanto esquemáticas como reales, de los parámetros estructurales de la AAP.

FIGURA 1. Diagramas esquemáticos representativos (izquierda) y micrografías SEM reales (derecha) de una AAP. (a) Vista de su sección transversal vertical y (b) vista superior indicando todos los parámetros geométricos que la caracterizan.
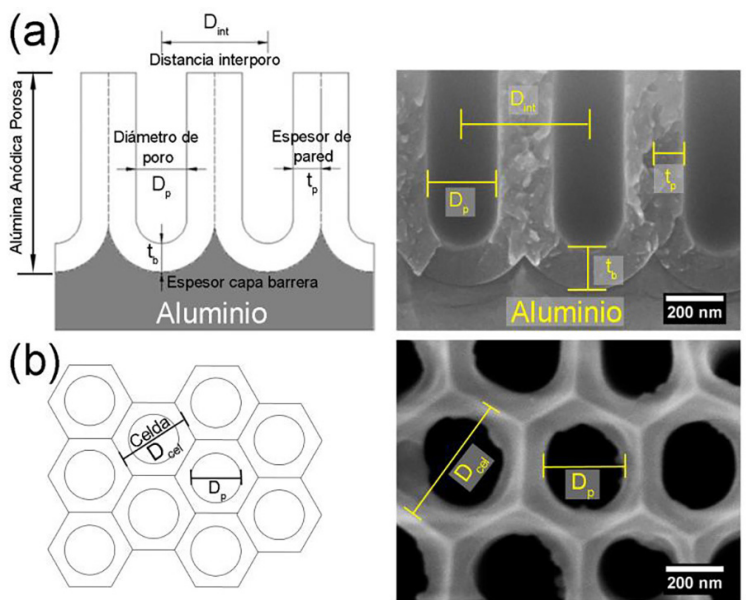

Fuente: Elaboración de los autores. 
En la figura 2 se presenta, de manera general, el procedimiento estándar para la obtención de una película de AAP sobre la superficie del aluminio metálico. La figura 2(a) muestra la superficie del aluminio después de la limpieza y pre-tratamientos; la 2(b), la superficie del aluminio después del pulido electroquímico; la figura 2(c), la parte superior de la película de AAP después del primer anodizado donde se evidencia el arreglo desordenado de nanoporos; la 2(d), la superficie del aluminio después de eliminar selectivamente la AAP. Dicha superficie metálica queda marcada con un arreglo de nanoconcavidades que sirven como puntos de nucleación para el crecimiento de una nueva película de AAP con poros ordenados. La figura 2(e) corresponde a la película de AAP después de un segundo anodizado, y, la 2(f), a la sección transversal (izquierda) y parte inferior (derecha) de la película de AAP después de eliminar selectivamente el aluminio, la base de los poros se muestra como un arreglo de nanodomos altamente ordenados.

\section{Modulación del tamaño y disposición de poros en la AAP}

Las películas de AAP sintetizadas por anodización electroquímica se han vuelto extremadamente populares durante los últimos años, pues han servido como moldes multifuncionales para la fabricación de diversas estructuras a escala nanométrica (Sulka, 2008). En años recientes, se han realizado esfuerzos sustanciales para ampliar el intervalo en la $\mathrm{D}_{\text {int }}$, o bien, incrementar el $\mathrm{D}_{\mathrm{p}}$, sin alterar demasiado el orden y la organización del arreglo de los nanoporos, ya

FIGURA 2. Etapas de un proceso típico de doble anodizado. Las imágenes superiores muestran una representación esquemática del procedimiento experimental para la síntesis de plantillas de AAP, mientras que las imágenes inferiores muestran las micrografias SEM del material real obtenido.
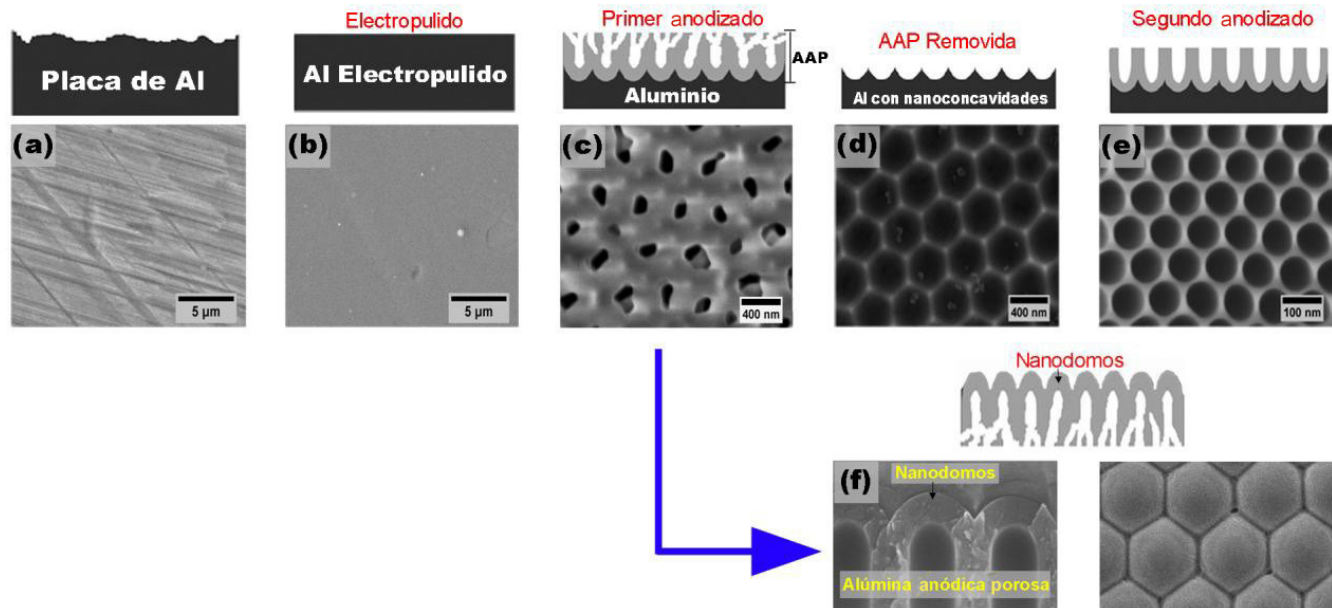

Fuente: Elaboración de los autores.
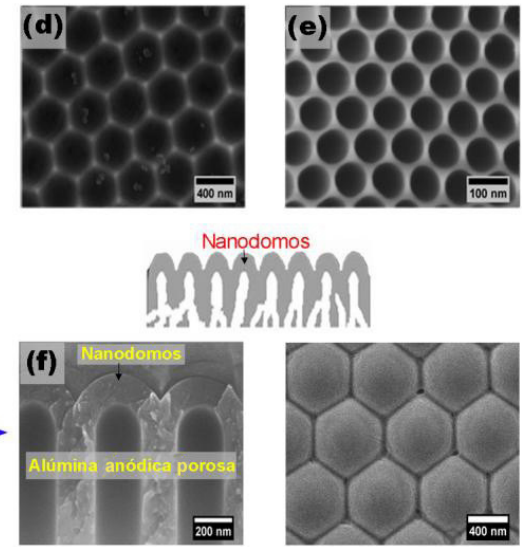
que para algunas aplicaciones resulta ser un factor crucial el conservar un alto grado de regularidad y uniformidad (Masuda, 2005; Wehrspohn, 2005). La distribución del $\mathrm{D}_{\mathrm{p}}$ y la $\mathrm{D}_{\text {int }}$ se pueden modular en función de diversos parámetros experimentales durante el anodizado electroquímico del aluminio. Por otro lado, se ha demostrado que el espesor de la $t_{b}$, determina el tamaño de la celda y del poro. También se ha encontrado experimentalmente que el $\mathrm{D}_{\mathrm{p}}$ y la $\mathrm{D}_{\text {int }}$ son directamente proporcionales al potencial de anodizado, así como la poca influencia que tiene la concentración y el tipo de electrolitos en el $\mathrm{D}_{\mathrm{p}}$. Sin embargo, en los procesos de anodizado convencionales (15-200 V), es posible obtener $\mathrm{D}_{\text {int }}$ en intervalos limitados dentro de 60-500 nm (Masuda et. al., 1997; Li et al., 1998; Jessensky et al., 1998; Nielsch et al., 2002; Zaraska et al., 2014); mientras que el uso de altos voltajes (mayores a $400 \mathrm{~V}$ ) ofrecen la posibilidad de obtener $\mathrm{D}_{\text {int }}$ entre 884-2036 nm (Chen et al., 2014; Ma et al., 2016; Wang et al., 2013).

Aunque la mayoría de las películas de AAP sintetizadas con altos voltajes tienen buena reproducibilidad y confiabilidad, todavía existen algunos problemas: los procesos de anodización requieren, generalmente, tiempos extremadamente largos (mayores a $24 \mathrm{~h}$ ) para obtener una disposición de poros altamente ordenados. También es necesario el uso de sistemas de enfriamiento complejos para mantener bajas temperaturas (menores a $0{ }^{\circ} \mathrm{C}$ ) y mantener las condiciones de anodización estables. Es bien sabido que al aplicar voltajes altos (mayores a $200 \mathrm{~V}$ ) durante un proceso de anodización, estos generan calor muy rápidamente causado por los campos eléctricos intensos, dando como resultado quemaduras o grietas macroscópicas observables en la superficie de la AAP debido a las reacciones químicas presentes ante los campos eléctricos intensos. Además, dan lugar a arreglos de poros más desordenados, es decir, mientras más alto sea el voltaje de anodizado mayor será el desorden de los poros. Debido a este hecho, la fabricación rápida y mecánicamente estable de películas de AAP usando voltajes altos sigue siendo un gran desafío.

Entre los electrolitos más comúnmente usados para conseguir $\mathrm{D}_{\text {int }}$ entre 50 y $600 \mathrm{~nm}$ usando potenciales de anodizado de hasta $400 \mathrm{~V}$ se encuentran: el ácido fosfórico $\left(\mathrm{H}_{3} \mathrm{PO}_{4}\right)$ (Li et al., 2006; Masuda et al., 1998; Xu et al., 2015; Zhang et al., 2010), malónico $\left(\mathrm{C}_{4} \mathrm{H}_{6} \mathrm{O}_{6}\right)$ (Knörnschild et al., 2015; Santos et al., 2012; Sun et al., 2013), cítrico $\left(\mathrm{C}_{6} \mathrm{H}_{8} \mathrm{O}_{7}\right)$ (Chen et al., 2014; Ma et al., 2016; Wang et al., 2013), acetilendicarboxílico o butinodioico $\left(\mathrm{C}_{4} \mathrm{H}_{2} \mathrm{O}_{4}\right)$ (Kikuchi et al., 2014a), selénico $\left(\mathrm{H}_{2} \mathrm{SeO}_{4}\right)$ (Akiya et al., 2015; Kikuchi et al., 2014b; Nazarkina et al., 2015; Nazarkina et al., 2017; Nishinaga et al., 2013), etidrónico (Kikuchi et al., 2015 y 2017), entre otros. Al aumentar el potencial de anodizado superior a los $400 \mathrm{~V}$, se ha optado por utilizar electrolitos a base de mezclas de ácidos y alcoholes los cuales actúan como difusores de calor en la celda electroquímica (Chen et al., 2014; Wang et al., 2013). En las figuras 3 y 4 se muestran imágenes de arreglos regulares de poros y domos de la capa barrera a diferentes voltajes de anodizado, respectivamente, en donde se utilizaron mezclas de diferentes ácidos, tales como el oxálico $\left(\mathrm{C}_{2} \mathrm{H}_{2} \mathrm{O}_{4}\right)$, fosfórico $\left(\mathrm{H}_{3} \mathrm{PO}_{4}\right)$ 
y cítrico $\left(\mathrm{C}_{6} \mathrm{H}_{8} \mathrm{O}_{7}\right)$ con etilenglicol (EG) (González-Campuzano et al., 2017 y 2019). Los factores que influyen en la regularidad de los arreglos nanométricos durante el proceso de síntesis electroquímica empiezan con el corte de las láminas de aluminio (de $0.25 \mathrm{~mm}$ de espesor y $99.999 \%$ de pureza), las cuales se someten a un tratamiento estandarizado de limpieza, liberación de esfuerzos mecánicos y acabado a espejo que garantiza la uniformidad y homogeneidad cristalina en la superficie metálica previo al proceso de anodizado electroquímico. La secuencia de pasos y su justificación es como sigue: la limpieza inicial de las placas de aluminio con acetona es para retirar residuos de grasa y polvo. Con el fin de aumentar el tamaño de grano y liberar esfuerzos mecánicos presentes debido al proceso de laminado y corte de las piezas de aluminio, se realiza un tratamiento térmico (llamado recocido) a $600{ }^{\circ} \mathrm{C} \mathrm{du}-$ rante 6 h en una atmósfera de $\mathrm{H}_{2}$ a presión atmosférica. Posteriormente, se elimina el óxido nativo y contaminantes orgánicos que pudieran formarse en la superficie del aluminio posterior al proceso de recocido, usando una disolución $0.25 \mathrm{M}$ de carbonanto de sodio $\left(\mathrm{Na}_{2} \mathrm{CO}_{2}\right)$ a $80{ }^{\circ} \mathrm{C}$ durante 3 minutos. Luego se realiza un proceso para neutralizar la superficie del aluminio, usando una disolución de ácido nítrico $\left(\mathrm{HNO}_{3}\right)$ al $35 \%$ en peso durante $30 \mathrm{~s}$. Subsecuentemente, las placas son electropulidas en una celda electroquímica usando como contra electrodo una placa de grafito y una mezcla de ácido perclórico $\left(\mathrm{HClO}_{4}\right)$ al $70 \%$ en peso, y etanol $\left(\mathrm{C}_{2} \mathrm{H}_{6} \mathrm{O}\right)$ en una proporción 1:5 V/V, aplicando un voltaje constante de $18 \mathrm{~V}$ durante 2 minutos manteniendo una temperatura de $3{ }^{\circ} \mathrm{C}$. Por último, las muestras son limpiadas secuencialmente con acetona, etanol y, finalmente, con agua desionizada mediante ultrasonicación durante 15 minutos para posteriormente dar inicio al proceso de anodizado. El voltaje de anodización y el electrolito correspondiente se muestran en la tabla 1. Debido a los altos voltajes que se utilizan, se adiciona EG, que actúa como difusor de calor en la celda electroquímica ayudando a reducir efectos de ruptura por quemaduras de la película de alúmina durante la reacción química exotérmica en el anodizado.

La celda electroquímica usada para el proceso de anodizado es colocada en un baño térmico con agua a temperatura ambiente para mantenerla constante durante $24 \mathrm{~h}$. La placa de grafito y la placa de aluminio (contraelectrodo y electrodo) se colocan a una distancia fija de separación de $1 \mathrm{~cm}$, con el fin de mantener el mismo campo eléctrico formado entre las placas debido al potencial aplicado. Las disoluciones se agitan continuamente para homogeneizar tanto la concentración del electrolito como la temperatura en la superficie de trabajo que se encuentra en contacto con el electrolito. Se utiliza una fuente de poder DC ajustable con un intervalo de voltajes entre 0 y $600 \mathrm{~V}$, y un intervalo de corrientes entre 0 y 0.5 A (BK PRECISION modelo 9185B). Para evitar problemas de sobrecarga en la fuente, cuando se trabaja con voltajes altos de anodizado, se procede con aumentos graduales del voltaje evitando rebasar el límite de corriente eléctrica soportada por la fuente. Estos aumentos se realizan por pasos hasta alcanzar el voltaje final de anodizado, teniendo especial 
precaución en mantener una corriente constante en el estado estacionario de crecimiento de la película de alúmina porosa.

TABLA 1. Voltajes y electrolitos utilizados para la fabricación de las membranas de AAP por medio de anodizado electroquímico de aluminio.

\begin{tabular}{|c|c|}
\hline Voltaje (V) & Electrolito \\
\hline 40 & $100 \mathrm{ml}$ de $\mathrm{H}_{2} \mathrm{C}_{2} \mathrm{O}_{4}(0.3 \mathrm{M})$ \\
\hline 100 & $100 \mathrm{ml}$ de $\mathrm{H}_{3} \mathrm{PO}_{4}(0.1 \mathrm{M})$ \\
\hline 150 & $80 \mathrm{ml}$ de $\mathrm{H}_{3} \mathrm{PO}_{4}(0.1 \mathrm{M})+20 \mathrm{ml}$ de $\mathrm{EG}$ \\
\hline 200 & $60 \mathrm{ml}$ de $\mathrm{H}_{3} \mathrm{PO}_{4}(0.05 \mathrm{M})+25 \mathrm{ml} \mathrm{de} \mathrm{C}_{6} \mathrm{H}_{8} \mathrm{O}_{7}(1 \mathrm{M})+40 \mathrm{ml}$ de EG \\
\hline 250 & $80 \mathrm{ml}$ de $\mathrm{H}_{3} \mathrm{PO}_{4}(0.01 \mathrm{M})+20 \mathrm{ml}$ de $\mathrm{C}_{6} \mathrm{H}_{8} \mathrm{O}_{7}(1 \mathrm{M})$ \\
\hline 300 & $20 \mathrm{ml}$ de $\mathrm{H}_{3} \mathrm{PO}_{4}(0.01 \mathrm{M})+80 \mathrm{ml}$ de $\mathrm{C}_{6} \mathrm{H}_{8} \mathrm{O}_{7}(1 \mathrm{M})$ \\
\hline 350 & $20 \mathrm{ml}$ de $\mathrm{H}_{3} \mathrm{PO}_{4}(0.01 \mathrm{M})+40 \mathrm{ml}$ de $\mathrm{C}_{6} \mathrm{H}_{8} \mathrm{O}_{7}(1 \mathrm{M})+50 \mathrm{ml}$ de EG \\
\hline 400 & $15 \mathrm{ml}$ de $\mathrm{H}_{3} \mathrm{PO}_{4}(0.01 \mathrm{M})+40 \mathrm{ml}$ de $\mathrm{C}_{6} \mathrm{H}_{8} \mathrm{O}_{7}(1 \mathrm{M})+50 \mathrm{ml}$ de $\mathrm{EG}$ \\
\hline 450 & $10 \mathrm{ml}$ de $\mathrm{H}_{3} \mathrm{PO}_{4}(0.01 \mathrm{M})+40 \mathrm{ml}$ de $\mathrm{C}_{6} \mathrm{H}_{8} \mathrm{O}_{7}(1 \mathrm{M})+50 \mathrm{ml}$ de $\mathrm{EG}$ \\
\hline 500 & $3 \mathrm{ml}$ de $\mathrm{H}_{3} \mathrm{PO}_{4}(0.01 \mathrm{M})+45 \mathrm{ml}$ de $\mathrm{C}_{6} \mathrm{H}_{8} \mathrm{O}_{7}(0.5 \mathrm{M})+45 \mathrm{ml}$ de EG \\
\hline 550 & $1 \mathrm{ml}$ de $\mathrm{H}_{3} \mathrm{PO}_{4}(0.01 \mathrm{M})+50 \mathrm{ml}$ de $\mathrm{C}_{6} \mathrm{H}_{8} \mathrm{O}_{7}(0.1 \mathrm{M})+50 \mathrm{ml}$ de EG \\
\hline 600 & $50 \mathrm{ml}$ de $\mathrm{C}_{6} \mathrm{H}_{8} \mathrm{O}_{7}(0.1 \mathrm{M})+50 \mathrm{ml}$ de $\mathrm{EG}$ \\
\hline
\end{tabular}

Fuente: González-Campuzano et al. (2017 y 2019).

Una vez terminado el proceso de anodizado, las muestras se limpian con agua desionizada mediante ultrasonicación durante 15 minutos. Aunque los parámetros elegidos para el anodizado aseguran un crecimiento regular de los poros en la AAP, sobre todo para tiempos de crecimiento prolongados, siempre es necesario realizar un proceso denominado anodizado de dos pasos, o proceso de doble anodizado. El procedimiento consiste en retirar la película de alúmina porosa formada en el primer anodizado, usando una mezcla de ácido fosfórico $\left(\mathrm{H}_{3} \mathrm{PO}_{4}\right)$ al $6 \%$ en peso, y trióxido de cromo $\left(\mathrm{CrO}_{3}\right)$ al $1.8 \%$ en peso a $60{ }^{\circ} \mathrm{C}$ durante $12 \mathrm{~h}$. Con este ataque selectivo de la película porosa se conservan las marcas en la superficie del aluminio, que corresponden a la forma inversa de la parte inferior de las celdas que constituyen el arreglo de poros, a estas nanoestructuras se les denomina nanoconcavidades (figura 2(d) y figura 5). Estas estructuras sirven como zonas de nucleación para el crecimiento de la nueva película porosa en el segundo proceso de anodizado. Este último se realiza bajo las mismas condiciones que el primero. La figura 2 esquematiza todas las etapas del método de anodización de dos pasos. El resultado del segundo anodizado mejora bastante el ordenamiento desde las primeras etapas de crecimiento en estas películas porosas y evita la generación de esfuerzos o tensiones mecánicas en el arreglo de las celdas de alúmina que se van formando en un espacio geométrico ya definido.

Finalmente, una vez formada la película de AAP mediante un segundo anodizado, el $\mathrm{D}_{\mathrm{p}}$ queda definido por las condiciones del anodizado (voltaje de trabajo, temperatura, concentración y tipo de electrolito). Sin embargo, este no es el único factor que puede definir el diámetro de poro final, también se puede modificar este valor mediante un ataque químico selectivo de- 
Mundo Nano | ARTículos DE REVISı́ón | www.mundonano.unam.mx

15(28), 1e-28e, enero-junio 2022 | https:/ / doi.org/10.22201/ceiich.24485691e.2022.28.69672

Ricardo González Campuzano, María Esther Mata Zamora

nominado ensanchamiento de poro, usando una disolución $0.5 \mathrm{M}$ de $\mathrm{H}_{3} \mathrm{PO}_{4}$ a $45^{\circ} \mathrm{C}$. Dependiendo de la naturaleza de la AAP se varía el tiempo de ataque. En nuestro caso se requirieron entre 30 y 60 minutos. Este proceso disuelve la pared de los poros de forma preferencialmente radial, haciendo que el diámetro de los mismos aumente al eliminar el material del que está constituida la pared del poro (figura 3).

FIGURA 3. Micrografias SEM de la vista superior de películas de AAP evidenciando nanoporos altamente ordenados después del proceso de anodizado de dos pasos. El valor del voltaje mostrado fue el utilizado durante el proceso de anodizado.
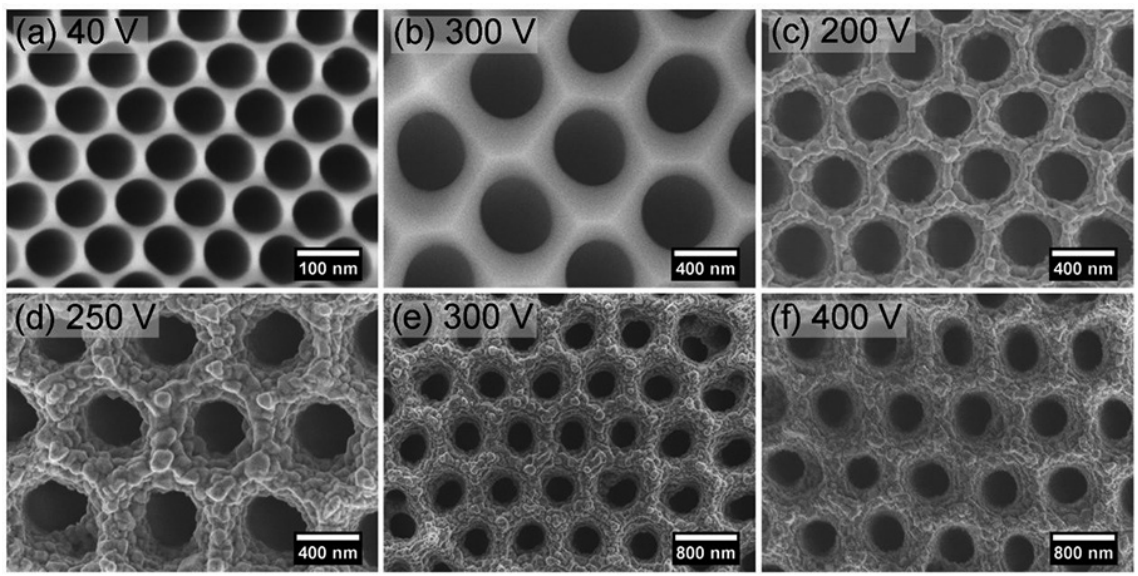

Fuente: Elaboración de los autores.

Los nanodomos (parte inferior de las celdas de AAP, correspondientes a la capa barrera) (figura 4) son sintetizados utilizando una variante del proceso de anodizado de dos pasos. Para ello, después del primer anodizado, se elimina el aluminio que aún queda sin anodizar y sirve de soporte a la película de AAP. Como la disposición experimental de la celda electroquímica utilizada en nuestros experimentos permite anodizar ambas caras de la placa de aluminio, el procedimiento es como sigue: para eliminar el sustrato metálico, primero se disuelve la película porosa de la cara opuesta a la de interés empleando una disolución de $2.5 \mathrm{M}$ de hidróxido de sodio $(\mathrm{NaOH})$ a temperatura ambiente. Una vez expuesto el aluminio, se elimina mediante un ataque electroquímico con una disolución al $20 \%$ en peso de ácido clorhídrico $(\mathrm{HCl})$. Como contra electrodo, se utiliza una placa de grafito y se aplica una diferencia de potencial entre 1 y $5 \mathrm{~V}$, a temperatura ambiente. La diferencia de potencial aplicada durante el proceso acelera la reacción entre los iones de cloro y el aluminio metálico sin atacar al óxido de aluminio en la película porosa que se encuentra en la cara posterior (capa barrera). Por último, se limpia la superficie con el arreglo de nanodomos mediante un ataque químico que elimina el aluminio residual usando una mezcla de ácido clorhídrico $\mathrm{HCl}$ al $20 \%$ en peso y cloruro de cobre $\left(\mathrm{CuCl}_{2}\right)$ 0.5 $\mathrm{M}$ a temperatura ambiente. 
FIGURA 4. Micrografías SEM de la vista superior de películas de AAP evidenciando nanodomos altamente ordenados posterior a la disolución selectiva del aluminio. El valor del voltaje mostrado fue el utilizado durante el proceso de anodizado.
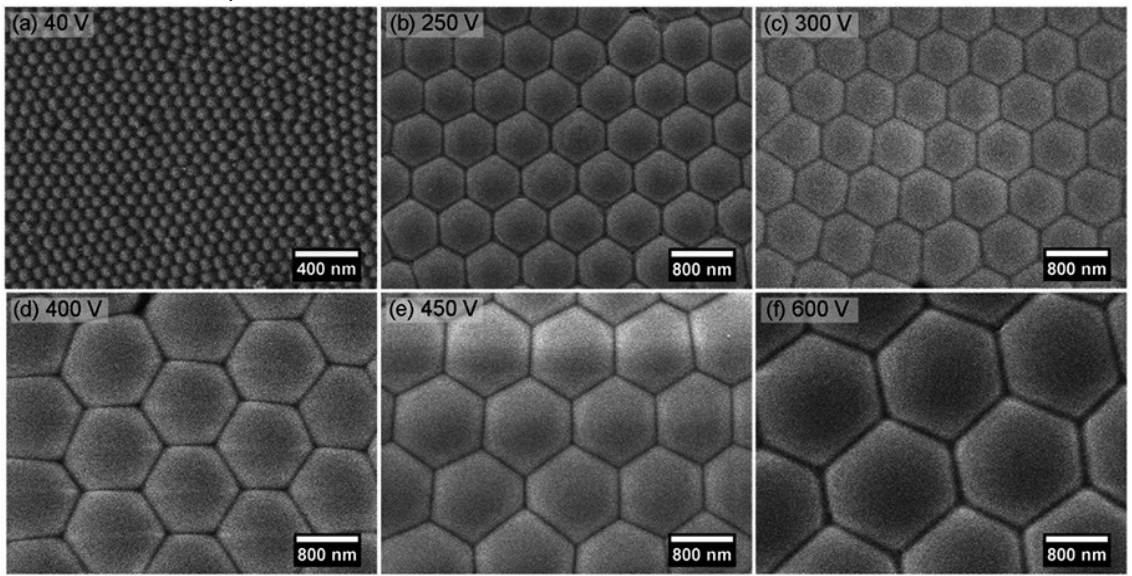

Fuente: Elaboración de los autores.

Como se mencionó anteriormente y resumiendo, además de las nanoestructuras porosas y los nanodomos que resultan del arreglo geométrico de las celdas de AAP, existen otro tipo de nanoestructuras que corresponden al arreglo geométrico formado en la superficie del aluminio después del primer anodizado, denominadas nanoconcavidades como las mostradas en las figuras 2(f) y 5 . Estas se forman en la superficie del aluminio después de disolver selectivamente la AAP. Los parámetros que caracterizan a estas nanoestructuras (nanoporos, nanodomos y nanoconcavidades) son el diámetro de poro, nanoconcavidad y nanodomo $\left(\mathrm{D}_{\mathrm{p}}\right)$, así como la distancia interporo, interconcavidad e interdomo $\left(\mathrm{D}_{\text {int }}\right)$. Estos parámetros son función del potencial de anodizado aplicado como se muestran en la figura 6. En dicha figura se observa que el tamaño de estas nanoestructuras depende del potencial aplicado, manteniendo una relación lineal entre ambos parámetros. Es por ello que el proceso de anodizado electroquímico del aluminio, en comparación con otras técnicas costosas como la litografía, es una buena alternativa porque permite obtener nanoestructuras con dimensiones deseadas al elegir apropiadamente el electrolito y el potencial de anodizado (Wehrspohn et al., 2005; Zaraska et al., 2015).

El panorama de las posibles aplicaciones que brindaría una membrana cerámica de $\mathrm{AAP}$ con un amplio intervalo en la modulación del tamaño de poro mayor a los $600 \mathrm{~nm}$, es de gran interés tecnológico en áreas de la ciencia e ingeniería de materiales. La mayor parte de este interés se basa en sus destacadas propiedades físicas y químicas y, más concretamente, en sus propiedades ópticas. La interacción de la luz con la AAP da lugar a una gran cantidad de propiedades ópticas que tienen su interés tanto a nivel de investigación como de aplicación. Por ejemplo, Leung et al. (2012) han demostrado que las membranas de AAP correctamente modificadas (con dimensiones de poro de 
Mundo Nano | ARTículos DE REVISıón | www.mundonano.unam.mx

15(28), 1e-28e, enero-junio 2022 | https://doi.org/10.22201/ceiich.24485691e.2022.28.69672

Ricardo González Campuzano, María Esther Mata Zamora

FIGURA 5. Micrografias SEM de la vista superior de las nanoconcavidades altamente ordenadas, formadas en la superficie del aluminio, posterior a la disolución selectiva de la AAP. El valor del voltaje mostrado fue el utilizado durante el proceso de anodizado.
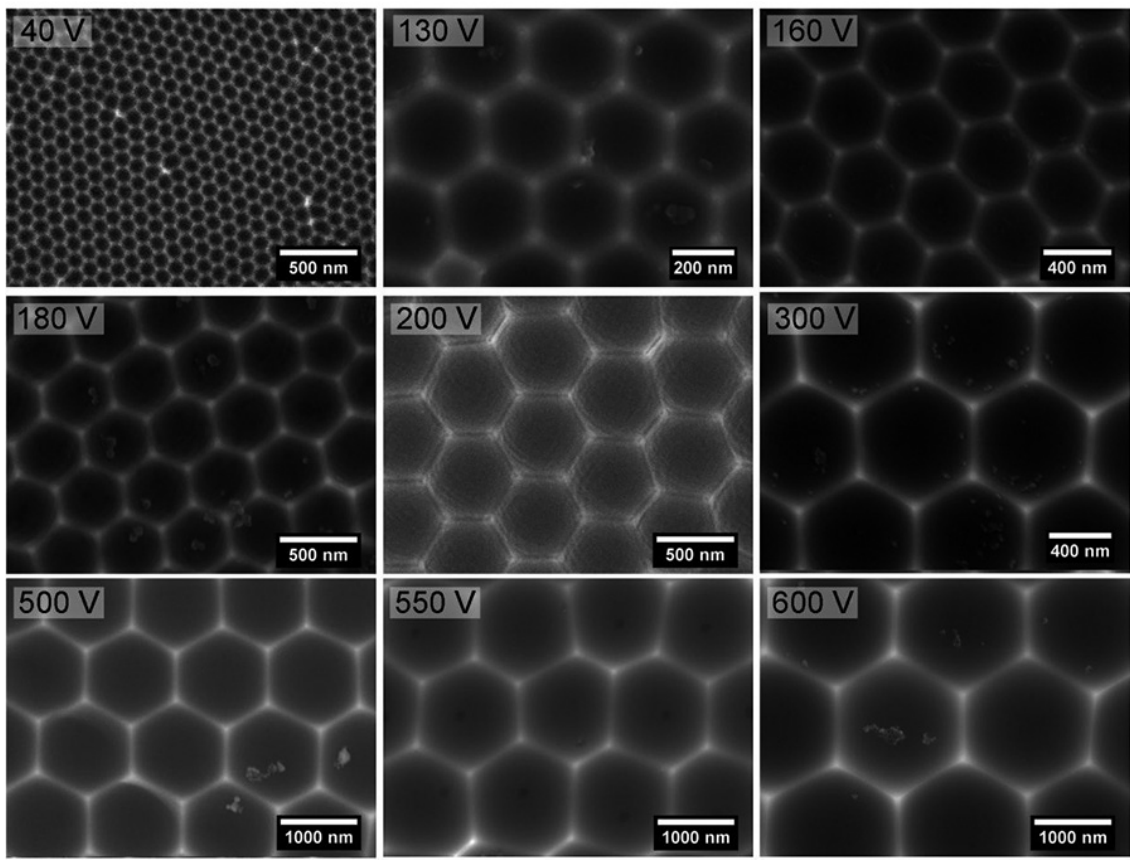

Fuente: Elaboración de los autores.

FIGURA 6. Relación entre los parámetros geométricos y el voltaje de anodizado aplicado $\left(V_{A}\right)$ para las diferentes nanoestructuras obtenidas a partir de la AAP. (a) Diámetro de nanoporo, nanoconcavidad y nanodomo $\left(D_{p}\right)$ vs $V_{A} ;(b)$ distancia interporo, interconcavidad e interdomo $\left(D_{\text {int }}\right)$ vs $V_{A}$.
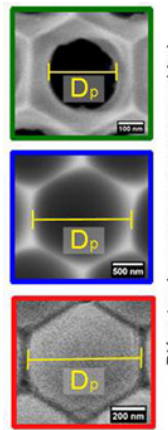

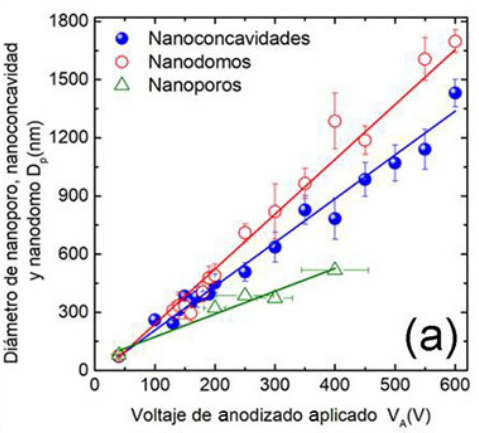

Fuente: Elaboración de los autores.

$\sim 700 \mathrm{~nm}$ ) pueden ser utilizadas como recolectores de luz eficientes en el intervalo de longitud de onda de $700 \mathrm{~nm}$. Es por ello que la modulación del tamaño de poro es crucial para determinadas aplicaciones. 


\section{Composición química de las celdas del óxido de aluminio anódico poroso}

El mecanismo de crecimiento de las AAP en electrolitos ácidos se basa principalmente en un equilibrio entre la formación de óxido de aluminio, impulsado por el campo eléctrico, intensificado en la interfaz óxido/metal en la base del poro y la disolución de óxido en la interfaz óxido/electrolito (figura 7). Cuando el aluminio se oxida anódicamente, los iones del electrolito son incorporados desde la base de los poros y los aniones migran a través de la película de alúmina formada por acción del campo eléctrico aplicado. Bajo las condiciones del mecanismo de crecimiento de la capa porosa, el campo eléctrico deja de ejercer acción en la migración de los aniones al alejarse de la base de los poros. De esta manera los aniones incorporados pasan a formar parte de óxido anódico que forma la pared de los poros (Thompson y Wood, 1981).

FIGURA 7. Ilustración esquemática de la sección transversal vertical (izda.) y vista superior (dcha.) de un arreglo de celdas de AAP. Se muestran las zonas o regiones diferenciadas por el contenido de los iones derivados del electrolito utilizado durante el anodizado del aluminio.

\section{Arreglo de celdas}

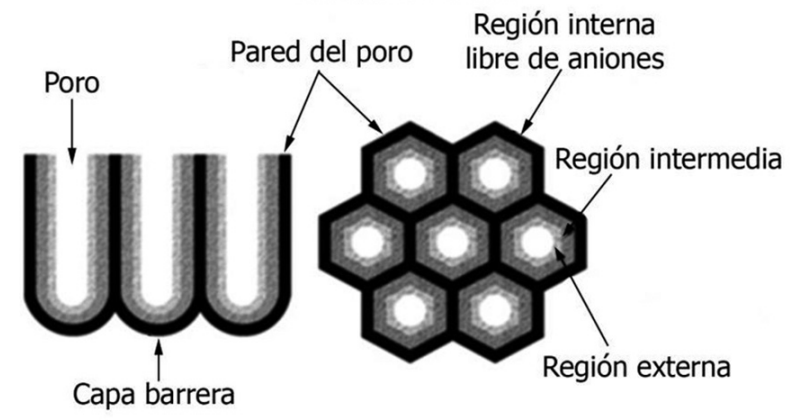

Fuente: Elaboración de los autores.

El resultado de este proceso es la formación de tres regiones diferenciadas por el contenido de los iones derivados del electrolito utilizado durante el anodizado electroquímico del aluminio. La base y la pared de los poros están constituidas por un porcentaje de alúmina relativamente pura (región interna), otro porcentaje de alúmina contaminada con aniones, con un máximo local intermedio (región intermedia) y un porcentaje de alúmina, que además de aniones, contiene protones y moléculas de agua (región externa), como se observa esquemáticamente en la figura 7 . La cantidad de las especies aniónicas incorporadas y su distribución en el óxido anódico de las celdas dependen del potencial de anodizado $\left(\mathrm{V}_{\mathrm{A}}\right)$, la densidad de corriente $(\mathrm{j})$, la temperatura ( $\mathrm{T})$, así como también del tipo y concentración de los electrolitos (Lee y Park, 2014). 


\section{Estabilidad térmica se las AAP}

Antes de hablar de las características térmicas de la AAP, es necesario mencionar aspectos generales de los óxidos de aluminio y su estructura cristalina. El sistema aluminio/oxígeno presenta una extensa variedad de estructuras de alúmina metaestable, que pueden ser identificadas como arreglo de cationes aluminio ordenados, o parcialmente ordenados, en los sitios intersticiales de una subred de oxígenos con un empaquetamiento aproximadamente compacto. El arreglo de los iones oxígeno se puede dividir en dos amplias categorías: las alúminas cúbicas centradas en las caras o alúminas de empaquetamiento hexagonal compacto. La distribución de los cationes dentro de cada subgrupo da origen a las diferentes formas del óxido de aluminio identificadas con letras griegas (Wefers y Misra, 1987). Las estructuras del óxido de aluminio con base en el empaquetamiento cúbico centrado en las caras incluyen las formas: $\gamma, \eta$ (cúbicas), $\theta$ (monoclínica), y la $\delta$ (ya sea tetragonal u ortorrómbica); mientras que las estructuras de alúmina con base en el empaquetamiento hexagonal compacto están representadas por las formas: $\alpha$ (trigonal), $\kappa$ (ortorrómbica) y la $\chi$ (hexagonal) (Levin y Brandon, 1998). Al seguir la nomenclatura Alcoa (Wefer y Misra, 1987), a excepción de la fase termodinámicamente estable $\alpha-\mathrm{Al}_{2} \mathrm{O}_{3}$, los demás óxidos de aluminio se les conoce como alúminas de transición, pues a partir de tratamientos térmicos cada una de las formas identificadas, son etapas de una continua transición entre estructuras cristalinas metaestables, hasta llegar a la fase estable corindón. En particular, las alúminas de transición formadas a bajas temperaturas contienen iones hidroxilo, la secuencia de transición no es reversible, es decir, ninguna $\alpha-\mathrm{Al}_{2} \mathrm{O}_{3}$ o cualquiera de las formas presentes a alta temperatura pueden ser convertidas a una de las alúminas de transición que aparecen a bajas temperaturas. Otro aspecto importante es que la microestructura del material de partida determina el tipo de secuencia de las transformaciones en el curso del tratamiento térmico (Levin y Brandon, 1998). En la tabla 2, se presentan algunas de las secuencias de transformación de diversos precursores que conducen a la fase $\alpha-\mathrm{Al}_{2} \mathrm{O}_{3}$, adicionalmente también se indica las temperaturas aproximadas a las cuales se forman las diferentes fases cristalinas.

Una vez establecido lo anterior, es conveniente recordar, de las secciones anteriores, que la AAP incorpora aniones producto de la reacción de anodizado en la celda electroquímica. La distribución y concentración dentro de la estructura del óxido de aluminio anódico de estos aniones depende de los parámetros experimentales en el proceso del anodizado. Como se mencionó anteriormente, se pueden identificar tres regiones: una zona de alúmina de alta pureza en la capa interna adyacente a la interface óxido/metal; una capa de óxido de aluminio intermedia constituida por aniones y una capa externa, adyacente a la interface óxido/electrolito formada por aniones, protones y moléculas de agua. Por tanto, es de esperar que la estabilidad térmica y resistencia química 
de las AAP, se vea afectada por el perfil de distribución de los aniones en la estructura del óxido de aluminio anódico.

TABLA 2. Estructuras y secuencias de transformación en los oxohidróxidos e hidróxidos de aluminio metaestables generados por diferentes rutas de partida.

\begin{tabular}{|c|c|}
\hline & $\alpha$-AlOOH (diáspora) $\stackrel{700-800^{\circ} \mathrm{C}}{\longrightarrow} \alpha-\mathrm{Al}_{2} \mathrm{O}_{3}$ \\
\hline hcp & $\begin{array}{l}\gamma-\mathrm{Al}(\mathrm{OH})_{3} \text { (gibsita) } \stackrel{150-300^{\circ} \mathrm{C}}{\longrightarrow} \chi \stackrel{650-750^{\circ} \mathrm{C}}{\longrightarrow} \kappa \stackrel{1000^{\circ} \mathrm{C}}{\longrightarrow} \alpha-\mathrm{Al}_{2} \mathrm{O}_{3} \\
5 \mathrm{Al}_{2} \mathrm{O}_{3} \mathrm{H}_{2} \mathrm{O} \text { (tohdita) } \stackrel{700-800^{\circ} \mathrm{C}}{\longrightarrow} \kappa \stackrel{750^{\circ} \mathrm{C}}{\longrightarrow} \kappa \stackrel{900^{\circ} \mathrm{C}}{\longrightarrow} \alpha-\mathrm{Al}_{2} \mathrm{O}_{3} \\
\text { Vapor (CVD) } \rightarrow \kappa \rightarrow \alpha-\mathrm{Al}_{2} \mathrm{O}_{3}\end{array}$ \\
\hline fcc & $\begin{array}{l}\gamma \text {-AlOOH (bohemita) } \stackrel{300-500^{\circ} \mathrm{C}}{\longrightarrow} \gamma \stackrel{700-800^{\circ} \mathrm{C}}{\longrightarrow} \delta \stackrel{900-1000^{\circ} \mathrm{C}}{\longrightarrow} \theta \stackrel{1000-1100^{\circ} \mathrm{C}}{\longrightarrow} \alpha-\mathrm{Al}_{2} \mathrm{O}_{3} \\
\alpha-\mathrm{Al}(\mathrm{OH})_{3} \text { (bayerita) } \stackrel{200-300^{\circ} \mathrm{C}}{\longrightarrow} \eta \stackrel{600-800^{\circ} \mathrm{C}}{\longrightarrow} \theta \stackrel{1000-1100^{\circ} \mathrm{C}}{\longrightarrow} \alpha-\mathrm{Al}_{2} \mathrm{O}_{3}\end{array}$ \\
\hline
\end{tabular}

Fuente: Adaptación de Levin y Brandon (1998).

A mediados de los años noventa del siglo pasado, se iniciaron una serie de estudios para analizar la composición y estructura de la AAP empleando técnicas de análisis térmico, complementadas con espectroscopía infrarroja y difracción de rayos-X. La técnica de análisis térmico diferencial (DTA, differential thermal analysis, por sus siglas en inglés) mide la diferencia en temperatura entre la muestra y un material de referencia inerte, en función de la temperatura. La técnica de calorimetría diferencial de barrido (DSC, differential scanning calorimetry, por sus siglas en inglés) mide el flujo de calor que es necesario suministrar a la muestra para mantenerla a temperatura idéntica a un material de referencia. Los picos endotérmicos y exotérmicos observados en las gráficas durante el tratamiento térmico usado en esta técnica pueden ser atribuidos a diferentes procesos, como la descomposición del material, la transformación de fases cristalinas, puntos de fusión, transiciones vítreas, entre otros. La identificación de estos procesos se puede realizar con el apoyo de técnicas como la difracción de rayos-X. El análisis termogravimétrico (TGA, thermogravimetric analysis, por sus siglas en inglés) mide la pérdida de masa al ir incrementando la temperatura, si a esta técnica se acopla un espectrómetro de absorción infrarrojo, es posible identificar alguno de los compuestos que son liberados por efecto de la descomposición del material al incrementar la temperatura (Wunderlich, 1990).

Estudios, como los de Mardilovich y Ozao (Mardilovich et al., 1995; Ozao et al., 2000, 2001a,b, 2002, 2003), establecieron que en las AAP ocurren una serie 
de etapas durante el tratamiento térmico en las que se ve involucrada la descomposición de las especies aniónicas incorporadas en el material y la secuencia de transformación de la alúmina amorfa a las alúminas de transición. La descripción del mecanismo de transformación resulta complejo, pues además intervienen los parámetros experimentales considerados en las técnicas del análisis térmico; tales como el programa de calentamiento, velocidad de calentamiento, el tipo de atmosfera (inerte, oxidante o reductora) y flujo del gas de arrastre (Ozao et al., 2000 y 2001a,b). No obstante, con el acoplamiento simultáneo de técnicas espectroscópicas como la absorción infrarroja, resonancia magnética nuclear (NMR, nuclear magnetic resonance) o técnicas como TG-MS (thermogravimetry-mass spectrometry), TG-DTA,TPD-MS (temperature programmed desorption-mass spectrograph), difracción de rayos-X (DRX), termoanálisis, se ha podido llegar a cierto conocimiento del proceso que se lleva a cabo en la transformación de las AAP desde su estado amorfo inicial, hasta llegar a la fase corindón y la composición de las especies aniónicas incorporadas en la estructura inicial.

El esquema general propuesto en la evolución térmica se ha establecido en las AAP más utilizadas, formadas en electrólitos ácidos (ácido sulfúrico, oxálico y fosfórico). Los estudios realizados con las técnicas de termoanálisis simultáneo (TG-DSC o DTA) han mostrado que las pérdidas de masa se deben a la deshidratación (desde temperatura ambiente a los $400^{\circ} \mathrm{C}$ ), deshidroxilación (entre $400^{\circ} \mathrm{C}-700^{\circ} \mathrm{C}$ ), y por arriba de los $700^{\circ} \mathrm{C}$ hasta los $960^{\circ} \mathrm{C}$, l a existencia de procesos colectivos en los que interviene la migración y pérdida de los aniones atrapados dentro del material, junto con el inicio de la formación de alúminas policristalinas (Mardilovich et al., 1995; Ozao et al., 2000, 2001a,b, 2002, 2003). A temperaturas por arriba de los $1100{ }^{\circ} \mathrm{C}$, las transiciones exhiben picos exotérmicos (curvas DTA o DSC) atribuidos a la formación de las alúminas de transición $\gamma, \theta, \delta\left(900{ }^{\circ} \mathrm{C}-1100{ }^{\circ} \mathrm{C}\right)$ y la fase más estable $\alpha-\mathrm{Al}_{2} \mathrm{O}_{3}$ $\left(1400^{\circ} \mathrm{C}\right)$. El perfil de las curvas DSC en estos trabajos muestra que los picos exotérmicos, debidos a la transformación de la alúmina amorfa a una de las alúminas de transición, resulta ser más alta (entre $250^{\circ} \mathrm{C}$ y $300^{\circ} \mathrm{C}$ ) que en las alúminas amorfas obtenidas por métodos químicos lo que se atribuye a que la presencia de los grupos aniónicos estabiliza la fase amorfa de la alúmina anódica, retardando la cristalización hasta que a una temperatura relativamente alta se da la transformación cristalina seguida por la descomposición de las especies aniónicas (Ozao et al., 2003; Mata y Saniger, 2005).

El proceso dinámico de la cristalización es diferenciado entre las alúminas formadas en ácido sulfúrico y ácido oxálico, en relación con las alúminas formadas en ácido fosfórico. La formación de las alúminas de transición y la eliminación de las especies aniónicas son procesos acoplados en las alúminas formadas en ácido sulfúrico u oxálico (Ozao et al., 2001a). Entre los $700{ }^{\circ} \mathrm{C}$ y 900 ${ }^{\circ} \mathrm{C}$ se producen cambios significativos de masa y energía producto de la transformación de la alúmina amorfa en policristalina. Las especies aniónicas, incorporadas durante el anodizado, se descomponen quedando atrapadas en 
forma gaseosa en la matriz de alúmina, produciendo con esto la alteración de la estructura de las celdas que forman los poros. Durante esta etapa llamada de amorfización, el diámetro de los poros cambia presentando expansión y contracción en las dimensiones del poro al liberarse los gases producto de la descomposición de las especies aniónicas (Ozao et al., 2002). A temperaturas más elevadas, la fase inicial policristalina, más la amorfa que aún prevalece, cristaliza en las formas metaestables. Inicia con la formación de la $\gamma$-alúmina y sigue con la coexistencia de las formas $\delta$ y $\theta$-alúmina, hasta los $1100^{\circ} \mathrm{C}$. A pesar de la temperatura elevada, se puede detectar una cantidad menor de sulfatos y oxalatos que se van eliminando a medida que sigue aumentando la temperatura. Finalmente, se forma la fase $\alpha-\mathrm{Al}_{2} \mathrm{O}_{3}$, alrededor de los $1250{ }^{\circ} \mathrm{C}$, libre de impurezas (Ozao et al., 2000, 2001b).

FIGURA 8. Curvas termogravimétricas de: (a) AAP sulfúrica; (b) AAP oxálica, y, (c) AAP fosfórica. Se indican los procesos de: (I) la deshidratación; (II) la deshidroxilación, y, (III) la descomposición de las especies aniónicas presentes en el óxido de aluminio anódico.

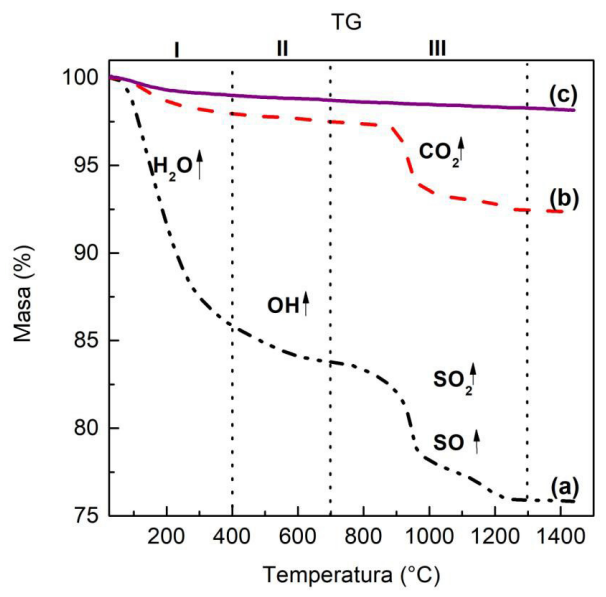

Fuente: Mata y Saniger (2005).

A nivel microestructural, se ha investigado, con la técnica de resonancia magnética nuclear $\left({ }^{27} \mathrm{Al}\right.$ aluminum NMR), cómo cambia la coordinación del aluminio a medida que incrementa la temperatura en la alúmina anódica. En las alúminas anódicas amorfas el aluminio se encuentra coordinado con el oxígeno en unidades de corto alcance formando tetraedros, pentaedros y octaedros $\left(\mathrm{AlO}_{4}, \mathrm{AlO}_{5}\right.$ y $\left.\mathrm{AlO}_{6}\right)$ (Farman, 1989); con el incremento de la temperatura, se transita de la fase amorfa a las diferentes formas cristalinas de las alúminas de transición en las que prevalecen las coordinaciones $\mathrm{AlO}_{4}$ y $\mathrm{AlO}_{6}$. Mientras que la coordinación $\mathrm{AlO}_{5}$ va disminuyendo, debido al proceso de formación de las alúminas de transición y la eliminación de los aniones presentes en el material (Cho et al., 2015). Al formarse las alúminas de transi- 
ción $\gamma, \delta, \theta$-alúminas las coordinaciones 4 y 6 se mantienen, ya que estas pertenecen a la simetría cúbica centrada en las caras (Kirchner et al., 2007). Al alcanzar la temperatura de transición a la $\alpha$-alúmina solo se encuentra la coordinación $\mathrm{AlO}_{6}$, que corresponde la simetría hexagonal compacta (Asoh et al., 2015; Aman et al., 2019).

En las gráficas de las figuras 8 y 9 se presentan, a manera de ejemplo, termogramas y curvas DTA de AAP formadas en los electrolitos más usados (ácidos sulfúrico, oxálico y fosfórico) y formadas en condiciones estándar de anodizado. Los voltajes, temperaturas y concentración de los electrolitos son los reportados para formar arreglos porosos uniformes (Nielsh et al., 2002). También las condiciones del programa térmico de los equipos corresponden a parámetros estándar, intervalo de temperatura, razón de calentamiento, atmosfera, gas de arrastre. Es importante mencionar esto, ya que en la literatura no siempre se trabaja con los mismos valores y esto puede modificar las temperaturas a las que se dan los cambios de fase (Aman et al., 2019; Norek et al., 2015; Ozao et al., 2001a,b).

Como se puede observar en la figura 8, en las pérdidas de masa registradas en los termogramas destacan los procesos de deshidratación y deshidroxilación entre temperatura ambiente y los $650^{\circ} \mathrm{C}$. Entre los $700^{\circ} \mathrm{C}$ y los $960^{\circ} \mathrm{C}$ se observa la pérdida de masa debido a la descomposición de las especies aniónicas $\left(\mathrm{SO}_{2}, \mathrm{CO}_{2}\right)$. El porcentaje de pérdida de masa en cada proceso dependerá de la preparación de las alúminas anódicas (Mata y Saniger, 2005). En el caso de las AAP formadas en ácido fosfórico su comportamiento térmico es muy distinto, como se puede observar en la curva termogravimétrica casi no hay pérdida de masa (figura 8 (c)). Los resultados de la espectroscopía infrarroja muestran que el grupo fosfato permanece incorporado en la matriz de alúmina, esta diferencia probablemente está relacionada con la estabilidad térmica de los fosfatos en la matriz de alúmina, debido a la alta afinidad química de los fosfatos por el aluminio (Bocchetta et al., 2003; Brown et al., 2006; Mata y Saniger, 2005).

En la figura 9, se comparan las curvas del análisis térmico diferencial de las tres alúminas anódicas. En las curvas se muestran los cambios que ocurren durante los procesos de deshidratación, deshidroxilación, descomposición de las especies aniónicas, junto con los cambios de fase de las alúminas anódicas. Los picos endotérmicos por abajo de los $400^{\circ} \mathrm{C}$ se atribuyen a los procesos de deshidratación y deshidroxilación. Entre los $800^{\circ} \mathrm{C}$ y $1100^{\circ} \mathrm{C}$ se encuentra el proceso de descomposición de las especies aniónicas junto con los procesos de transformación de fase, picos exotérmicos. En el caso de las alúminas formadas en ácido sulfúrico y oxálico la fase $\alpha-\mathrm{Al}_{2} \mathrm{O}_{3}$ se forma por arriba de los $1200{ }^{\circ} \mathrm{C}$; mientras que para las AAP formadas en ácido fosfórico su comportamiento es diferente. Entre los $1200^{\circ} \mathrm{C}$ y $1450{ }^{\circ} \mathrm{C}$ se forman las fases $\alpha-\mathrm{Al}_{2} \mathrm{O}_{3}$ y puesto que el grupo fosfato permanece incorporado en la matriz de alumina, el fosfato de aluminio $\left(\mathrm{AlPO}_{4}\right)$ coexiste como una segunda fase con la $\alpha$-alúmina cristalina (Bocchetta et al., 2003; Brown et al., 2006; Mata y Saniger, 2005). 
FIGURA 9. Curvas del análisis térmico diferencial para: (a) AAP sulfúrica; (b) AAP oxálica ,y, (c) AAP fosfórica. Se indican las alúminas de transición frecuentemente formadas entre los $800{ }^{\circ} \mathrm{C}$ y $1200^{\circ} \mathrm{C}$. La $\alpha-\mathrm{Al}_{2} \mathrm{O}_{3}$ se forma por arriba de los $1200^{\circ} \mathrm{C}$.

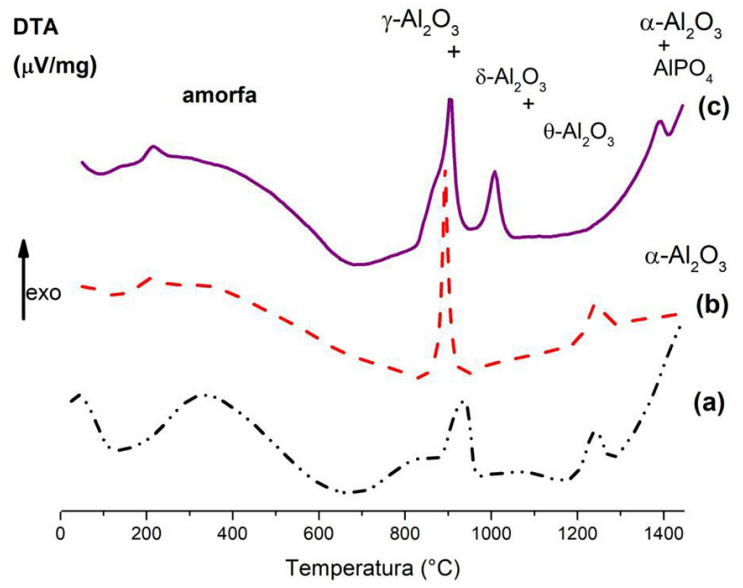

Fuente: Elaboración de los autores.

En reportes más recientes (Hashimoto et al., 2018a), se ha estudiado la formación de una estructura de mesoporos en la pared de las celdas al ser eliminadas las nanopartículas de fosfato de aluminio con el tratamiento térmico adecuado. Cabe mencionar que la formación de los mesoporos también se puede encontrar en las alúminas que contienen oxalatos y sulfatos, pero a temperaturas más bajas $\left(\sim 1000^{\circ} \mathrm{C}\right)$. Al incrementar la temperatura para formar la fase alfa-alúmina, los mesoporos son eliminados por acción de la sinterización del material de las paredes de las celdas (Roslyakov et al., 2020).

En la tabla 3, se reporta la ruta de transformación de las alúminas de transición a partir de la AAP. Los intervalos de temperatura son valores promedio de diversos trabajos (Aman et al., 2019; Asoh et al., 2015; Bocchetta et al., 2003; Brown et al., 2006; Chang et al., 2012; Cho et al., 2015; Choudhari et al., 2012; Hashimoto et al., 2018; Kirchner et al., 2007; Le Coz et al., 2010; Mardilovich et al., 1995; Masuda et al., 2015; Mata y Saniger, 2005; Mc Quaig et al., 2011; Ono et al., 2014; Ozao et al., 2000, 2001; Roslyakov et al., 2020; $\mathrm{Xu}$ et al., 2004).

En los trabajos más recientes (Chang et al., 2012; Hashimoto et al., 2018; Masuda et al., 2015; Roslyakov et al., 2020) relacionados con el tema de las membranas de $\alpha$-alúmina porosa se investigan las condiciones más adecuadas para obtener membranas estables y resistentes al ataque químico de bases y ácidos. Se establece que la estructura y composición de las celdas que forman el arreglo de poros es determinante en la estrategia a seguir para conservar la estructura. Los retos a vencer son varios, entre ellos está el de eliminar los aniones de las regiones intermedia y externa de la pared de las celdas, sin afectar la capa interna formada de alúmina relativamente pura y compacta (fi- 
gura 7). El segundo reto es no adelgazar el espesor de la pared de la celda durante el proceso de apertura y homogenización del diámetro superior e inferior de los poros. Otro reto es alcanzar un área extensa y plana de la membrana de $\alpha$-alúmina porosa con resistencia mecánica y sin fracturas.

TABLA 3. Ruta de transformación de las alúminas de transición a partir de la AAP. +AAP-Oxálica. Anodizado a 150 V; AAP-Oxálica. Anodizado entre 10 V y 130 V; *AAP-Oxálica. Anodizado a 130 V; **AAPFosfórica comercial (Wathman Anopore).

\begin{tabular}{|c|c|c|c|c|}
\hline Transición $\left({ }^{\circ} \mathrm{C}\right)$ & \multicolumn{3}{|c|}{ Amorfa $\rightarrow \gamma \rightarrow \delta \rightarrow \theta \rightarrow \alpha-\mathrm{Al}_{2} \mathrm{O}_{3}$} & Referencia \\
\hline AAP-sulfúrica & $\begin{array}{l}900 \\
850\end{array}$ & $\begin{array}{l}960-1240 \\
1150\end{array}$ & $\begin{array}{l}1250 \\
1300\end{array}$ & $\begin{array}{l}\text { Ozao et al. (2000, 2001a); Mata y Saniger (2005); } \\
\text { Kirchner et al. (2007). }\end{array}$ \\
\hline AAP-oxálica & $\begin{array}{l}800 \\
870 \\
870\end{array}$ & $\begin{array}{l}1075-1100 \\
870 \\
870 \\
903 \\
1100 \\
912 \\
800-950\end{array}$ & $\begin{array}{l}1150 \\
1200 \\
1219 \\
1400 \\
1210 \\
1100 \\
1200 \\
1200\end{array}$ & $\begin{array}{l}\text { Mardilovich et al. (1995); } \$ \text { Lee et al. (2000); } \\
\text { Bocchetta et al. (2003); Yang et al. (2003); } \\
\text { Mata y Saniger (2005); Kirchner et al. (2008) } \\
\text { +Xu et al. (2004); McQuaig et al. (2011) Ono et al. } \\
\text { (2014). } \\
\text { Cho et al. (2015); Masuda et al. (2015); } \\
\text { Aman et al. (2019).* }\end{array}$ \\
\hline AAP-fosfórica & $\begin{array}{l}700 \\
800- \\
900\end{array}$ & $\begin{array}{l}890 \\
920-1150 \\
850 \\
900-1100\end{array}$ & $\begin{array}{l}\mathrm{AlPO}_{4}+\alpha-\mathrm{Al}_{2} \mathrm{O}_{3} \\
1450 \\
1020-1300 \\
1300-1400\end{array}$ & $\begin{array}{l}\text { Bocchetta et al. (2003); Mata y Saniger (2005); } \\
\text { Brown et al. (2006); **Le Coz et al. (2010); } \\
\text { Cho et al. (2015); Masuda et al. (2015). }\end{array}$ \\
\hline
\end{tabular}

Fuente: Elaboración de los autores.

En las indicaciones generales sugeridas en los trabajos de Masuda (2015) y Roslyacov (2020), para mejorar las propiedades mecánicas de las membranas de $\alpha$-alúmina, se recuperan varias consideraciones experimentales mencionadas desde hace varias décadas. Entre ellas: la preparación del aluminio con tratamientos de recocido térmico para eliminar las tensiones mecánicas y aumentar el tamaño de grano en la superficie del metal; trabajar en las condiciones óptimas de anodizado (voltaje, corriente, temperatura, concentración del electrolito) para obtener el mayor ordenamiento posible de poros; mejorar la simetría en las dimensiones del poro a lo largo de la celda, eliminando o reduciendo el espesor de la capa barrera, aplicando procedimientos electroquí- 
micos al finalizar el anodizado; eliminar los aniones integrados a la AAP, por medio del ataque químico selectivo (Mardilovich, 1995; Jessensky et al., 1998; Masuda et al., 1997; Lee et al., 2000; Brown et al., 2006; Ono et al., 2014).

En la primera década de este siglo, la investigación ha tomado un enfoque más dirigido a cubrir aspectos importantes relacionados con el desarrollo tecnológico con el fin de obtener un material cerámico nanoporoso. El conocimiento más detallado de las regiones diferenciadas, presentes en la pared de la AAP, ha permitido desarrollar estrategias que toman en cuenta el conocimiento de los procesos dinámicos involucrados en la evolución de las fases policristalinas y la descomposición química de los aniones junto con los parámetros del tratamiento térmico implicado. Se ha establecido que una baja razón de calentamiento e inclusión de isotermas próximas a las temperaturas de descomposición de los aniones y/o de transición de fases son indispensables para evitar la acumulación de tensiones mecánicas en el material (Roslyakov et al., 2020). Por el momento, los datos experimentales se han restringido a las AAP sintetizadas usando los tres electrolitos más comunes, sin embargo, se abre un campo de investigación y desarrollo tecnológico para continuar con las alúminas de poros extra grandes. Las condiciones de anodizado en este tipo de AAP son poco convencionales, empezando por los altos voltajes de anodizado (>200 V) y el empleo de mezcla de ácidos y alcoholes en los electrolitos utilizados.

\section{Nuevas aplicaciones potenciales de las AAP}

Las películas de AAP sin tratamiento térmico ofrecen una amplia versatilidad para fabricar nanomateriales multifuncionales (Sousa et al., 2014) como los mostradas en la figura 10 para algunas aplicaciones potenciales. En la superficie del arreglo de nanoporos se pueden depositar metales y formar sistemas con nanohuecos que presentan propiedades novedosas e interesantes en aplicaciones tecnológicas (figura 10a). Estos nanohuecos, en comparación con las películas continuas, pueden producir efectos cuánticos en su conductividad (Nakanishi y Ando, 1996; Uryu y Ando, 1998), transmisión óptica mejorada (Ebbesen et al., 1998; Ruan y Qiu, 2006), propiedades plasmónicas (Schmidt et al., 2014; Schwind, et al., 2013), entre otros (Leitao et al., 2013; Vavassori et al., 2002; Wang et al., 2006). En la figura $10 \mathrm{~b}$ se muestra un arreglo de nanoalambres de níquel (Ni) embebidos en los nanoporos sintetizados mediante electrodepósito. Este tipo de nanoestructuras unidimensionales (1D) poseen numerosas propiedades catalíticas (Riva et al., 2019), magnéticas (Li et al., 2020), termoeléctricas (Domínguez-Adame et al., 2019), y ópticas (Quan et al., 2019; Yao et al., 2008). En las figuras 10 c y $10 d$ se muestran nanoconcavidades de aluminio y nanodomos de AAP, respectivamente. Recientemente, este tipo de nanoestructuras han adquirido gran interés debido a sus propiedades plasmónicas aprovechadas en la fabricación de sustratos para la detección de moléculas de interés químico y/o biológico (Celik et al., 2018; González-Campuzano et al., 2017; González-Campuzano et al., 2018; Huang y Tsai, 2018; Wang et al., 
Mundo Nano | ARTículos DE REVISıón | www.mundonano.unam.mx

15(28), 1e-28e, enero-junio 2022 | https://doi.org/10.22201/ceiich.24485691e.2022.28.69672

Ricardo González Campuzano, María Esther Mata Zamora

2012). También han servido como sustratos nanoestructurados para controlar propiedades plasmónicas de otros metales en diferentes intervalos de longitud de onda del espectro electromagnético (González-Campuzano y Mendoza, 2019; González-Campuzano et al., 2020). Las AAP con tratamiento térmico podrían ampliar su funcionalidad en aplicaciones en las que se requiere soportar condiciones de alta temperatura o medios corrosivos.

Adicionalmente, pueden ser usadas como filtros debido a su capacidad para bloquear selectivamente diversos tipos de virus, pequeñas moléculas orgánicas, sales y otros iones metálicos peligrosos. Song et al. (2011) informan sobre la preparación de AAP para eliminar iones peligrosos de metales pesados de una solución acuosa. La estructura porosa de las membranas de AAP facilita una mejor aceptación de catalizadores, por lo que se han propuesto como soportes catalíticos (Stair et al., 2006), e, incluso, se han propuesto en la separación de gases (Cho et al., 2015) y en la fabricación de microsensores. Aprovechando su transparencia moderada y un bajo coeficiente de absorción, también podrían utilizarse en dispositivos relacionados con la energía y la óptica. De hecho, se han incorporado en la fabricación de dispositivos LCD (Hong et al., 2010).

FIGURA 10. Micrografias SEM de diferentes nanoestructuras obtenidas a partir de las AAP: (a) arreglos de nanoporos; (b) nanoalambres; (c) nanoconcavidades, y, (d) nanodomos. Cabe aclarar que el falso color en las micrografias no tiene ningún significado particular, solo se utiliza con fines decorativos.
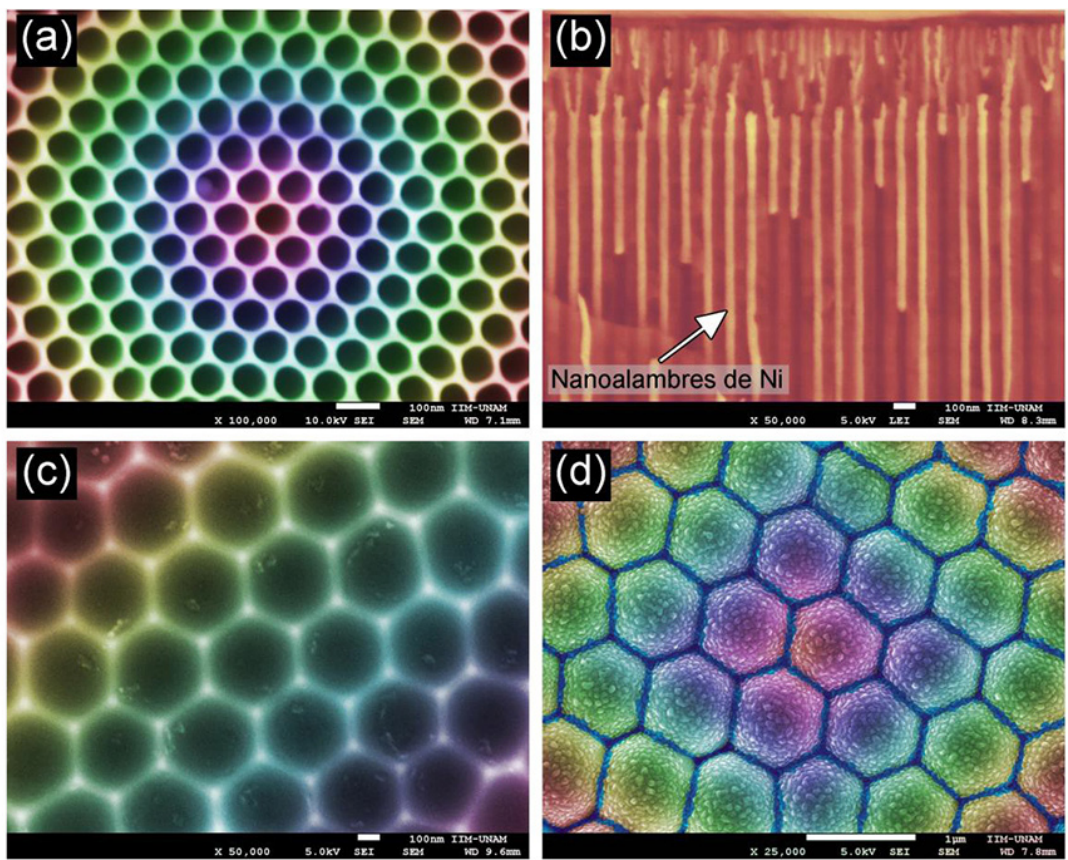

Fuente: Elaboración de los autores. 


\section{Conclusiones}

La anodización electroquímica del aluminio para la obtención de películas continúas o porosas de alúmina son actualmente objetos de una extensa investigación, con casi mil artículos publicados anualmente en el campo. En este manuscrito, se realizó una breve revisión acerca de la estructura y composición de las celdas de la AAP, así como de las rutas para conseguir membranas de $\alpha$-alúmina mediante tratamientos térmicos adecuados para conservar el arreglo de poros. Aunque hay avances notables en comprender el efecto de los aniones incorporados durante el anodizado, aún se requiere de investigación en otro tipo de electrolitos y condiciones de anodizado no convencionales. El reto consiste en conocer la composición, distribución y efecto de los aniones incorporados en las nuevas condiciones (por ejemplo, usando altos voltajes), y plantear estrategias que permitan evaluar su efecto en las propiedades de estabilidad térmica del material poroso en su fase cristalina alfa. Este campo de investigación se encuentra en auge, aunque las bases del conocimiento de las propiedades estructurales, morfológicas y térmicas es el producto de una gran cantidad de trabajos dedicados al estudio del óxido de aluminio anódico poroso desde la década de los años 50s. En general, la motivación que surge por el interés sostenido durante tanto tiempo en las AAP, es que se las considera también como un material modelo, cuyas características morfológicas ofrecen gran versatilidad para la síntesis, caracterización y estudio de propiedades fisicoquímicas de diferentes nanoestructuras funcionales sin la necesidad de procesos costosos como la litografía; así como el desarrollo de aplicaciones rentables basadas en la amplia extensión de los arreglos ordenados que se pueden obtener.

\section{Referencias}

Abdel-Karim, R. y El-Raghy, S. M. (2016). Fabrication of nanoporous alumina. En Nanofabrication using nanomaterials. One Central Press (OCP).

Akiya, S., Kikuchi, T., Natsui, S. y Suzuki, R. O. (2015). Optimum exploration for the self-ordering of anodic porous alumina formed via selenic acid anodizing. Journal of The Electrochemical Society, 162(10): E244-E250. https://doi. org/10.1149/2.0391510jes

Aman, J. N., Wied, J. K., Alhusaini, Q., Müller, S., Diehl, K., Staedler, T., Schönherr, H. Jiang, X., Schmedt, auf der Günne J. (2019). Thermal hardening and defects in anodic aluminum oxide obtained in oxalic acid: implications for the template synthesis of low-dimensional nanostructures. ACS Applied Nano Materials, 2(4): 1986-1994. https://doi.org/10.1021/acsanm.9b00018

Asoh, H., Masuda, T. y Ono, S. (2015). Nanoporous $\alpha$-alumina membranes with pore diameters tunable over wide range of 30-350 nm. ECS Transactions, 69(2): 225. https://doi.org/10.1149/06902.0225ecst

Bocchetta, P., Sunseri, C., Chiavarotti, G. y Di Quarto, F. (2003). Microporous alumina membranes electrochemically grown. ElectrochimicaActa, 48(20-22), 3175- 
3183. https://doi.org/10.1016/S0013-4686(03)00348-7

Brown, I. W. M., Bowden, M. E., Kemmitt, T. y MacKenzie, K. J. D. (2006). Structural and thermal characterisation of nanostructured alumina templates. Current Applied Physics 6(3): 557-561. https://doi.org/10.1016/j.cap.2005.11.060

Celik, M., Altuntas, S. y Buyukserin, F. (2018). Fabrication of nanocrater-decorated anodic aluminum oxide membranes as substrates for reproducibly enhanced SERS signals. Sensors and Actuators B: Chemical, 255: 2871-2877. https://doi. org/10.1016/j.snb.2017.09.105

Chang, Y., Ling, Z., Liu, Y., Hu, X. y Li, Y. (2012). A simple method for fabrication of highly ordered porous $\alpha$-alumina ceramic membranes. Journal of Materials Chemistry, 22(15): 7445-7448. https://doi.org/10.1039/C2JM15279G

Chen, X., Yu, D., Cao, L., Zhu, X., Song, Y., Huang, H., Lu, L. y Chen, X. (2014). Fabrication of ordered porous anodic alumina with ultra-large interpore distances using ultrahigh voltages. Materials Research Bulletin, 57: 116-120. https://doi. org/10.1016/j.materresbull.2014.05.037

Cho, S. Y., Kim, J. W. y Bu, S. D. (2015). Effects of impurities on phase transition changes according to heat treatment of porous anodic alumina fabricated in oxalic acid and phosphoric acid electrolytes. Journal of the Korean Physical Society, 66(9): 1394-1400. https://doi.org/10.3938/jkps.66.1394

Choudhari, K. S., Sudheendra, P. yUdayashankar, N. K. (2012). Fabrication and high- temperature structural characterization study of porous anodic alumina membranes. Journal of Porous Materials, 19(6): 1053-1062. https://doi. org/10.1007/s10934-012-9568-z

Domínguez-Adame, F., Martín-González, M., Sánchez, D. y Cantarero, A. (2019). Nanowires: A route to efficient thermoelectric devices. Physica E: Low-dimensional Systems and Nanostructures. 113: 213-225. http://dx.doi.org/10.1016/j. physe.2019.03.021

Ebbesen, T. W., Lezec, H. J., Ghaemi, H. F., Thio, T. y Wolff, P. A. (1998). Extraordinary optical transmission through sub-wavelength hole arrays. Nature, 391(6668): 667-669. https://doi.org/10.1038/35570

Farnan, I., Dupree, R., Jeong, Y., Thompson, G. E., Wood, G. C. y Forty, A. J. (1989). Structural chemistry of anodic alumina. Thin Solid Films, 173(2). 209-215. https://doi.org/10.1016/0040-6090(89)90136-3

Gitzen, W. H. (1970). Alumina as a ceramic material. Alcoa Research Laboratories. The American Ceramic Society Inc. EUA.

González-Campuzano, R., Martínez-Lara, D. E. y Mendoza, D. (2020). Lead plasmonics on texturized substrates: Pbmetafilms. Applied Physics Letters, 117(3): 031603. https://doi.org/10.1063/5.0016131

González-Campuzano, R., Mata-Zamora, M. E., López-Romero, S. y Mendoza, D. (2018). Excitation of plasmonic resonances within UV-Vis wave length range using low-purity aluminum nanoconcave arrays. Applied Physics Letters, 113(22): 221604. https://doi.org/10.1063/1.5059556

González-Campuzano, R., Saniger, J. M. y Mendoza, D. (2017). Plasmonic resonances in hybrid systems of aluminum nanostructured arrays and few layer gra- 
phene within the UV-IR spectral range. Nanotechnology, 28(46): 465704. https://doi.org/10.1088/1361-6528/aa8ce4

González-Campuzano, R. y Mendoza, D. (2019). Excitation of plasmons in self-ordered arrays of aluminum and silver nanoconcaves within UV-IR spectral range. Journal of Physics: Conference Series, 1221(1): 012001. https://doi.org/10.1088/17426596/1221/1/012001

Hashimoto, H., Kojima, S., Sasaki, T. y Asoh, H. (2018a). $\alpha$-Alumina membrane having a hierarchical structure of straight macropores and mesopores inside the pore wall. Journal of the European Ceramic Society, 38(4), 1836-1840. https:// doi.org/10.1016/j.jeurceramsoc.2017.11.032

Hashimoto, H., Shigehara, Y., Ono, S. y Asoh, H. (2018b). Heat-induced structural transformations of anodic porous alumina formed in phosphoric acid. Microporous and Mesoporous Materials, 265, 77-83. https://doi.org/10.1016/j.micromeso.2018.01.008

Hong, C., Tang, T. T., Hung, C. Y., Pan, R. P. y Fang, W. (2010). Liquid crystal alignment in nanoporous anodic aluminum oxide layer for LCD panel applications. Nanotechnology, 21(28): 285201. https://doi.org/10.1088/0957-4484/21/28/285201. https:// doi.org/10.1016/j.physe.2019.03.021

Huang, C. Y., Y Tsai, M. S. (2018). Fabrication of 3D nano-hemispherical cavity array plasmonic substrate for SERS applications. International Journal of Optomechatronics, 12(1): 40-52. https://doi.org/10.1080/15599612.2018.1508528

Jessensky, O., Müller, F. y Gösele, U. (1998). Self-organized formation of hexagonal pore arrays in anodic alumina. Applied physics letters, 72(10): 1173-1175. https:// doi.org/10.1063/1.121004

Kikuchi, T., Nishinaga, O., Natsui, S. y Suzuki, R. O. (2014a). Fabrication of anodic nanoporous alumina via acetylenedicarboxylic acid anodizing. ECS Electrochemistry Letters, 3(7): C25-C28. https://doi.org/10.1149/2.0071407eel

Kikuchi, T., Nishinaga, O., Natsui, S. y Suzuki, R. O. (2014b). Self-ordering behavior of anodic porous alumina via selenic acid anodizing. Electrochimica Acta, 137: 728-735. https://doi.org/10.1016/j.electacta.2014.06.078

Kikuchi, T., Nishinaga, O., Natsui, S. y Suzuki, R. O. (2015). Fabrication of self-ordered porous alumina via etidronic acid anodizing and structural color generation from submicrometer-scale dimple array. Electrochimica Acta, 156: 235-243. https://doi.org/10.1016/j.electacta.2014.12.171

Kikuchi, T., Takenaga, A., Natsui, S. y Suzuki, R. O. (2017). Advanced hard anodic alumina coatings via etidronic acid anodizing. Surface and Coatings Technology, 326: 72-78. https://doi.org/10.1016/j.surfcoat.2017.07.043

Kirchner, A., MacKenzie, K. J. D., Brown, I. W. M., Kemmitt, T. y Bowden, M. E. (2007). Structural characterisation of heat-treated anodic alumina membranes prepared using a simplified fabrication process. Journal of Membrane Science, 287(2): 264-270. https://doi.org/10.1016/j.memsci.2006.10.045

Knörnschild, G., Poznyak, A. A., Karoza, A. G. y Mozalev, A. (2015). Effect of the anodization conditions on the growth and volume expansion of porous alumina films in malonic acid electrolyte. Surface and Coatings Technology, 275: 
17-25. https://doi.org/10.1016/j.surfcoat.2015.04.030

Le Coz, F., Arurault, L. y Datas, L. (2010). Chemical analysis of a single basic cell of porous anodic aluminium oxide templates. Materials Characterization, 61(3): 283-288. https://doi.org/10.1016/j.matchar.2009.12.008

Lee, C. W., Kang, H. S., Chang, Y. H. y Hahm, Y. M. (2000). Thermo treatment and chemical resistance of porous alumina membrane prepared by anodic oxidation. Korean Journal of Chemical Engineering, 17(3): 266-272. https://doi.org/10.1007/ BF02699038

Lee, W. y Park, S. J. (2014). Porous anodic aluminum oxide: anodization and templated synthesis of functional nanostructures. Chemical Reviews, 114(15): 7487-7556. https://doi.org/10.1021/cr500002z

Leitao, D. C., Ventura, J., Teixeira, J. M., Sousa, C. T., Pinto, S., Sousa, J. B. Michalik, J. M., De Teresa, J. M., Vazquez, M. y Araujo, J. P. (2013). Correlations among magnetic, electrical and magneto-transport properties of Ni Fe nano hole arrays. Journal of Physics: Condensed Matter, 25(6): 066007. https://doi. org/10.1088/0953-8984/25/6/066007

Leung, S. F., Yu, M., Lin, Q., Kwon, K., Ching, K. L., Gu, L., ... y Fan, Z. (2012). Efficient photon capturing with ordered three-dimensional nanowell arrays. Nano letters, 12(7): 3682-3689. https://doi.org/10.1021/nl3014567

Levin, I. y Brandon, D. (1998). Metastable alumina polymorphs: crystal structures and transition sequences. Journal of the American Ceramic Society, 81(8): 19952012. https://doi.org/10.1111/j.1151-2916.1998.tb02581.x

Li, A. P., Müller, F., Birner, A., Nielsch, K. y Gösele, U. (1998). Hexagonal pore arrays with a 50-420 nm interpore distance formed by self-organization in anodic alumina. Journal of applied physics, 84(11): 6023-6026. https://doi.org/10.1063/1.368911

Li, H., Long, Y., Wang, X., Song, G., Ma, L., Xu, H. y Li, X. (2020). Controllable fabrication and magnetic properties of $\mathrm{Nd} / \mathrm{Co}$ core/shell nanowires. Applied Nanoscience, 1-8. https://doi.org/10.1007/s13204-020-01588-4

Li, Y., Zheng, M., Ma, L. y Shen, W. (2006). Fabrication of highly ordered nanoporous alumina films by stable high-field anodization. Nanotechnology, 17(20): 5101. https://doi.org/10.1088/0957-4484/17/20/010

Losic D., Santos A., (2015). Nanoporous alumina. fabrication, structure, properties and applications. Springer Series in Materials Science, Vol. 219, Springer. 10.1007/978-3319-20334-8

Ma, Y., Wen, Y., Li, J., Li, Y., Zhang, Z., Feng, C. y Sun, R. (2016). Fabrication of selfordered alumina films with large interpore distance by janus anodization in citric acid. Scientific Reports, 6: 39165. https://doi.org/10.1038/srep39165

Mardilovich, P. P., Govyadinov, A. N., Mukhurov, N. I., Rzhevskii, A. M. y Paterson, R. (1995). New and modified anodic alumina membranes. Part I. Thermotreatment of anodic alumina membranes. Journal of Membrane Science, 98(1-2): 131-142. https://doi.org/10.1016/0376-7388(94)00184-Z

Mardilovich, P. P., Govyadinoy, A. N., Mazurenko, N. I. y Paterson, R. (1995). New and modified anodic alumina membranes. Part II. Comparison of solubility of amorphous (normal) and polycrystalline anodic alumina membranes. Journal of mem- 
branescience, 98(1-2):143-155.https://doi.org/10.1016/0376-7388(94)00185-2

Masuda H. (2005). Highly ordered nanohole arrays in anodic porous alumina. En Ordered porous nanostructures and applications. Springer International Publishing. https://doi.org/10.1007/0-387-25193-6_3

Masuda, H., Hasegwa, F. y Ono, S. (1997). Self-ordering of cell arrangement of anodic porous alumina formed in sulfuric acid solution. Journal of the Electrochemical Society, 144(5): L127-L130. https://doi.org/10.1149/1.1837634

Masuda, H., Yada, K. y Osaka, A. (1998). Self-ordering of cell configuration of anodic porous alumina with large-size pores in phosphoric acid solution. Japanese Journal of Applied Physics, 37(11A): L1340. https://doi.org/10.1143/ JJAP.37.L1340

Masuda, T., Asoh, H., Haraguchi, S. y Ono, S. (2015). Fabrication and characterization of single phase $\alpha$-alumina membranes with tunable pore diameters. Materials, 8(3): 1350- 1368. https://doi.org/10.3390/ma8031350

Mata-Zamora, M. E. y Saniger, J. M. (2005). Thermal evolution of porous anodic aluminas: a comparative study. Revista Mexicana de Física, 51(5): 502-509.

McQuaig, M. K., Toro, A., Van Geertruyden, W. y Misiolek, W. Z. (2011). The effect of high temperature heat treatment on the structure and properties of anodic aluminum oxide. Journal of Materials Science, 46(1): 243-253. https://doi. org/10.1007/s10853-010-4966-6

Nakanishi, T. y Ando, T. (1996). Quantum interference effects in antidot lattices in magnetic fields. Physical Review B, 54(11): 8021. https://doi.org/10.1103/PhysRevB.54.8021

Nazarkina, Y., Gavrilov, S., Terryn, H., Petrova, M. y Ustarroz, J. (2015). Investigation of the ordering of porous anodic alumina formed by anodization of aluminum in selenic acid. Journal of The Electrochemical Society, 162(9): E166-E172. https://doi.org/10.1149/2.0571509jes

Nazarkina, Y., Kamnev, K., Dronov, A., Dudin, A., Pavlov, A. y Gavrilov, S. (2017).

Features of porous anodic alumina growth in galvanostatic regime in selenic acid based electrolyte. Electrochimica Acta, 231:327-335. https://doi.org/10.1016/j. electacta.2017.02.049

Nielsch, K., Choi, J., Schwirn, K., Wehrspohn, R. B. y Gösele, U. (2002). Self-ordering regimes of porous alumina: the 10porosity rule. Nano Letters, 2(7): 677-680. https://doi.org/10.1021/nl025537k

Nishinaga, O., Kikuchi, T., Natsui, S. y Suzuki, R. O. (2013). Rapid fabrication of selfordered porous alumina with 10-/sub-10-nm-scale nanostructures by selenic acid anodizing. Scientific Reports, 3: 2748. https://doi.org/10.1038/srep02748

Norek, M., Dopierała, M. y Stępniowski, W. J. (2015). Ethanol influence on arrangement and geometrical parameters of aluminum concaves prepared in a modified hard anodization for fabrication of highly ordered nanoporous alumina. Journal of Electroanalytical Chemistry, 750: 79-88. https://doi.org/10.1016/j. jelechem.2015.05.024

Ono, S., Nakamura, M., Masuda, T. y Asoh, H. (2014). Fabrication of nanoporous crystalline alumina membrane by anodization of aluminum. Materials Science 
Forum, 783: 1470-1475. Trans Tech Publications Ltd. https:/doi.org/10.4028/ www.scientific.net/MSF.783-786.1470

Ozao, R., Ochiai, M., Ichimura, N., Takahashi, H. e Inada, T. (2000). DSC study of alumina materials-applicability of transient DSC (Tr-DSC) to anodic alumina (AA) and thermoanalytical study of AA. Thermochimica Acta, 352: 91-97. https://doi. org/10.1016/S0040-6031(99)00443-8

Ozao, R., Ochiai, M., Yoshida, H., Ichimura, Y. e Inada, T. (2001a). Preparation of $\gamma$ alumina membranes from sulphuric electrolyte anodic alumina and its transition to $\alpha$-alumina. Journal of Thermal Analysis and Calorimetry, 64(3): 923-932. https://doi.org/10.1023/A:1011518929708

Ozao, R., Yoshida, H. e Inada, T. (2002). Morphological and structural change of nano-pored alumina membrane above $1200 \mathrm{~K}$. Journal of Thermal Analysis and Calorimetry, 69(3): 925-931. https://doi.org/10.1023/a:1020624526552

Ozao, R., Yoshida, H., Ichimura, Y., Inada, T. y Ochiai, M. (2001b). Crystallization of anodic alumina membranes studied by simultaneous TG-DTA/FTIR. Journal of Thermal Analysis and Calorimetry, 64(3): 915-922.https://doi.org/10.1023/a: 1011566811961

Ozao, R., Yoshida, H., Inada, T. y Ochiai, M. (2003). Sulfur concentration in nanoporous alumina membrane. Journal of Thermal Analysis and Calorimetry, 72(1): 113118. https://doi.org/10.1023/a:1023959401129

Quan, L. N., Kang, J., Ning, C. Z. y Yang, P. (2019). Nanowires for photonics. Chemical Reviews, 119(15): 9153-9169. https://doi.org/10.1021/acs.chemrev.9b00240

Riva, J. S., Juárez, A. V., Urreta, S. E. y Yudi, L. M. (2019). Catalytic properties of FePd ferromagnetic nanowires at liquid/liquid interfaces. Electrochimica Acta, 298: 379-388. https://doi.org/10.1016/j.electacta.2018.12.069

Roslyakov, I. V., Kolesnik, I. V., Levin, E. E., Katorova, N. S., Pestrikov, P. P., Kardash, T. Y., y Napolskii, K. S. (2020). Annealing induced structural and phase transitions in anodic aluminum oxide prepared in oxalic acid electrolyte. Surface and Coatings Technology, 381, 125159. https://doi.org/10.1016/j.surfcoat.2019.125159

Roslyakov, I. V., Shirin, N. A., Berekchiian, M. V., Shatalova, T. B., Garshev, A. V. y Napolskii, K. S. (2020). Coarse-grain alpha-alumina films with highly ordered porous structure. Microporous and Mesoporous Materials, 294: 109840. https:// doi.org/10.1016/j.micromeso.2019.109840

Ruan, Z. y Qiu, M. (2006). Enhanced transmission through periodic arrays of subwave length holes: the role of localized waveguide resonances. Physical Review Letters, 96(23): 233901. https://doi.org/10.1103/PhysRevLett.96.233901

Runge, J. M. (2018). A brief history of anodizing aluminum. in: the metallurgy of anodizing aluminum. Connecting science to practice. USA: Springer International Publishing. https://doi.org/10.1007/978-3-319-72177-4_2

Santos, A., Alba, M., Rahman, M. M., Formentín, P., Ferré-Borrull, J., Pallarès, J. y Marsal, L. F. (2012). Structural tuning of photoluminescence in nanoporous anodic alumina by hard anodization in oxalic and malonic acids. Nanoscale Research Letters, 7(1): 228. https://doi.org/10.1186/1556-276X-7-228

Schmidt, T. M., Bochenkov, V. E., Espinoza, J. D. A., Smits, E. C., Muzafarov, A. M., 
Kononevich, Y. N. y Sutherland, D. S. (2014). Plasmonic fluorescence enhancement of DBMBF2 monomers and DBMBF2-toluene exciplexes using al-hole arrays. The Journal of Physical Chemistry C, 118(4): 2138-2145. https://doi. org/10.1021/jp4110823

Schwind, M., Kasemo, B. y Zoric, I. (2013). Localized and propagating plasmons in imetal films with nanoholes. NanoLetters, 13(4): 1743-1750. https://doi.org/10.1021/ nl400328x

Song, J., Oh, H., Kong, H. y Jang, J. (2011). Polyrhodanine modified anodic aluminum oxide membrane for heavy metal ions removal. Journal of Hazardous Materials, 187(1- 3): 311-317. https://doi.org/10.1016/j.jhazmat.2011.01.026

Sousa, C. T., Leitao, D. C., Proenca, M. P., Ventura, J., Pereira, A. M. y Araujo, J. P. (2014). Nanoporous alumina as templates for multifunctional applications. Applied Physics Reviews, 1(3): 031102. https://doi.org/10.1063/1.4893546

Stair, P. C., Marshall, C., Xiong, G., Feng, H., Pellin, M. J., Elam, J. W. y Wang, H. H. (2006). Novel, uniform nanostructured catalytic membranes. Topics in catalysis, 39(3-4), 181-186. https://doi.org/10.1007/s11244-006-0055-0

Sulka, G. D. (2008). Highly ordered anodic porous alumina formation by self-organized anodizing. Nanostructured Materials in Electrochemistry, 1: 1-116. https:// doi.org/10.1002/9783527621507.ch1

Sun, B., Li, J., Jin, X., Zhou, C., Hao, Q. y Gao, X. (2013). Self-ordered hard anodization in malonic acid and its application in tailoring alumina taper-nanopores with continuously tunable periods in the range of 290-490 nm. Electrochimica Acta, 112: 327- 332. https://doi.org/10.1016/j.electacta.2013.08.147

Thompson, G. E. y Wood, G. C. (1981). Porous anodic film formation on aluminium. Nature 290:230-232. https://doi.org/10.1038/290230a0

Uryu, S. y Ando, T. (1998). Numerical study of localization in antidotlattices. Physical Review B, 58(16): 10583. https://doi.org/10.1103/PhysRevB.58.10583

Vavassori, P., Gubbiotti, G., Zangari, G., Yu, C. T., Yin, H., Jiang, H. y Mankey, G. J. (2002). Lattice symmetry and magnetization reversal in micron-size antidot arrays in Permalloy film. Journal of Applied Physics, 91(10): 7992-7994. https:// doi.org/10.1063/1.1453321

Wang, C. C., Adeyeye, A. O. y Singh, N. (2006). Magnetic antidot nanostructures: effect of lattice geometry. Nanotechnology, 17(6): 1629. https://doi.org/10.1088/09574484/17/6/015

Wang, J., Huang, L., Zhai, L., Yuan, L., Zhao, L., Zhang, W., Dongzhi, S., Hao, A., Feng, X. y Zhu, J. (2012). Hot spots engineering in hierarchical silver nanocap array for surface-enhanced Raman scattering. Applied Surface Science, 261: 605-609. https://doi.org/10.1016/j.apsusc.2012.08.063

Wang, Q., Long, Y. y Sun, B. (2013). Fabrication of highly ordered porous anodic alumina membrane with ultra-large pore intervals in ethylene glycol-modified citric acid solution. Journal of Porous Materials, 20(4): 785-788. https://doi. org/10.1007/s10934-012-9653-3

Wefers, K. yMisra, C. (1987). Oxides and hydroxides of aluminum, 19: 1-92. Pittsburgh, PA: Alcoa Laboratories. 
Wehrspohn, R. B. (2005). Ordered porous nanostructures and applications. EUA: Springer International Publishing. https://doi.org/10.1007/b106900

Wunderlich, B. (1990). Thermal analysis. EUA: Academic Press, INC.

Xu, W. L., Zheng, M. J., Wu, S. y Shen, W. Z. (2004). Effects of high-temperature annealing on structural and optical properties of highly ordered porous alumina membranes. Applied Physics Letters, 85(19): 4364-4366. https://doi.org/10.1063/1.1815072

Xu, Y. F., Liu, H., Li, X. J., Kang, W. M., Cheng, B. W. y Li, X. J. (2015). A novel method for fabricating self-ordered porous anodic alumina with wide interpore distance using phosphoric/oxalic acid mixed electrolyte. Materials Letters, 151: 79-81. https://doi.org/10.1016/j.matlet.2015.03.049

Yang, S. G., Li, T., Huang, L. S., Tang, T., Zhang, J. R., Gu, B. X. y Lu, Y. N. (2003). Stability of anodic aluminum oxide membranes with nanopores. Physics Letters A, 318(4-5): 440-444. https://doi.org/10.1016/j.physleta.2003.09.051

Yao, J., Liu, Z., Liu, Y., Wang, Y., Sun, C., Bartal, G., Stacy, G. M. y Zhang, X. (2008).Optical negative refraction in bulk metamaterials of nanowires. Science, 321(5891): 930- 930. https://doi.org/10.1126/science.1157566

Zaraska, L., Stępniowski, W. J., Jaskuła, M. y Sulka, G. D. (2014). Analysis of nanopore arrangement of porous alumina layers formed by anodizing in oxalic acid at relatively high temperatures. Applied Surface Science, 305: 650-657. https://doi. org/10.1016/j.apsusc.2014.03.154

Zaraska, L., Wierzbicka, E., Kurowska-Tabor, E. y Sulka, G. D. (2015). Nanoporous alumina: fabrication, structure, properties, applications. Switzerland: Springer International Publishing. https://doi.org/10.1007/978-3-319-20334-8

Zhang, R., Jiang, K. y Ding, G. (2010). Surface morphology control on porous anodic alumina in phosphoric acid. Thin Solid Films, 518(14): 3797-3800. https:// doi.org/10.1016/j.tsf.2010.01.004 